\title{
CEP 16-01
}

\section{Estimation of Health Care Demand and its Implication on Income Effects of Individuals}

Hossein Kavand

Carleton University
Marcel-Cristian Voia

Carleton University

January 2016; revised 26 June 2017

\section{CARLETON ECONOMIC PAPERS}
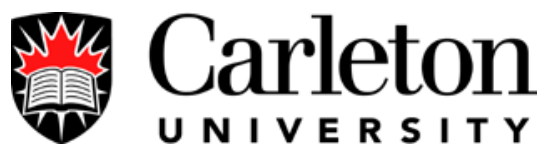

Department of Economics

1125 Colonel By Drive Ottawa, Ontario, Canada K1S 5B6 


\title{
Estimation of health care demand and its implication on income effects of individuals
}

\author{
Hossein Kavand* \\ hosseinkavand@cmail.carleton.ca \\ Marcel Voia** \\ marcel.voia@carleton.ca
}

May 2017

\begin{abstract}
Zero inflation and over-dispersion issues can significantly affect the predicted probabilities as well as lead to unreliable estimations in count data models. This paper investigates whether considering this issue for German Socioeconomic Panel (1984-1995), used by Riphahn et al (2003), provides any evidence of misspecification in their estimated models for adverse selection and moral hazard effects in health demand market The paper has the following contributions: first, it shows that estimated parameters for adverse selection and moral hazard effects are sensitive to the model choice; second, the random effects panel data as well as standard pooled data models do not provide reliable estimates for health care demand (doctor visits); third, it shows that by appropriately accounting for zero inflation and over-dispersion there is no evidence of adverse selection behaviour and that moral hazard plays a positive and significant role for visiting more doctors. These results are robust for both males and females’ subsamples as well as for the full data sample.
\end{abstract}

Key words: Over-dispersion, zero-inflated distribution, adverse selection, moral hazard, health demand JEL classifications: C46, C52, I11, I13.

\section{Introduction and literature review}

Pauly (1968), Rothschild and Stiglitz (1976), and Bundorf et al.( 2005), respectively, delineate the effect of moral hazard, adverse selection, and income effect in health insurance markets. A number of studies have investigated these effects, though sometimes different econometric methodologies led to different interpretations about the effects of similar data.

Following the model developed by Cameron et al. (1988), Rephahn et al (2003) we estimate the demand for doctor and hospital visits for the German Socioeconomic Panel data (GSOEP, 1984-1995). The findings of this study suggest that adverse selection, where a high-risk individual buys more insurance coverage, affects positively the number of doctor and hospital visits for only the males' hospital demand. 
Moral hazard, where an insured individual uses more health care services because of its lower cost, does not have any significant effect on any of the above health-care demands. Among other studies that looked at the effect of asymmetry information on health care demand are the studies of Chiappori and Salani (2000) that examined adverse selection using German data, while Geil et al. (1997) and Cameron et al. (1988) investigate moral hazard using Australian data.

In their theoretical model, Wolfe and Goddeeris (1991) delineate that wealth can ambiguously affect health-care demand. Their empirical results, however, indicate that both "bequeathable” and "nonbequeathable" wealth substantially increase the demand for both supplementary health care and health expenditure. Data reveals that those who enrolled for supplementary insurance, on average, had 50 percent higher wealth. They estimate the effect of moral hazard in a health expenditure model and use its estimated error term as a proxy for unexplained expenditure in their health care demand model. Its significant coefficient indicate the existence of selection effect.

For U.S. data, Marvasti (2014) finds that the demand for services of doctors is neither income elastic nor price elastic. As Marvasti discusses, however, Bago d’Uva and Jones’ (2009) latent hurdle model confirms a positive income effect on the number of visiting doctors for European data. Amponsah (2013) confirms moral hazard and adverse selection for Ghanaian health care, and finds that an individual in a higher income group to be more likely to buy health insurance (income effect). His study confirms the income effect found in Asante and Aikins (2008) and Kirigia et al. (2005).

Keane and Stavrunova (2016) use a simultaneous equation model to jointly investigate adverse selection and moral hazard for the U.S. supplemental health-insurance market, namely Medigap. They extend previous studies by employing a smooth mixture of the Tobit model to control for heterogeneity, and by capturing the correlation between unobservable factors that affect both health insurance demand and health expenditure. Although they find a negligible adverse selection into Medigap, the insurance coverage leads to a significant rise in health care utilization and its related costs (moral hazard). Conditional on the supplemental insurance and health status, income has a small effect on health expenditure (See Cardon and Hendel (2001) and Bajari et al. (2011, 2014) for other health market structural models).

To deal with inflated zeros in health care demand variables, researchers rely on different approaches. Powell and Goldman (2016) control for zero medical care expenditure and its heavily-skewed distribution by employing a quantile treatment effect framework (see Powell (2014)). The framework estimates an unconditional distribution for health care expenditures by assuming no adverse selection. 
They compare this distribution with the observed health expenditure distribution to estimate adverse selection effects. After separating moral hazard and adverse selection, each factor almost explains half of the reason for higher medical expenditure of a most generous plan compared to a least one.

With around $90 \%$ and $35 \%$ zeros for the number of doctor visits and hospital visits, the results of Rephahn et al (2003) can also suffer from over-dispersion by not taking them into account. To mitigate the random effects, they mix a Poisson distribution with log-normal distribution; however, the approach may not account for the over-dispersion. In this paper, we estimate different versions of generalized standard distributions and zero-inflated models discussed by Harris et al (2014) and Hilb (2011).

We investigate how accounting for inflated zeros impacts the effects of moral hazard effects and adverse selection, which affects how individuals allocate their income to health care. We examine the importance of over-dispersion in the data, and select the model that results in more accurate predictions for the data from Rephahn et al (2003). Comparing with Rephahn et al (2003), the selected Zero-Inflated Negative Binomial2 (ZINB2) model estimates the impact of the adverse selection and moral hazard on health-care demand in a consistent way.

A number of papers have extended the application of zero-inflated models. Greene (1994) considers the zero-inflated negative binomial (ZINB). As Ainsworth (2007) argues, ZINB model is used by Neal and Gaher (2006) to study drug use issues among college students; Gupta et al (1996) and Famoye and Singh (2006) apply a zero-inflated Generalize Poisson model to study frequentist setting. Ainsworth (2007) points out that Zero-inflated models have been further developed, in Ecology, by Ridout et al (1998), Martin et al (2005) and Kuhnert et al (2005) to explain different kinds of zeros: those that are structural as well as those that depend on the study. Hill (2011) provides details of other papers, for example, Cohen (1960), Johnson et al (2005) for underscore zeros, Mekerssoon and Roth (2000), Li et al (2003) for situations where data have inflated zero ${ }^{1}$.

The outline of the paper is as follows. Section 2 discusses the different methodologies that are employed in this paper. Section 3 describes the data used in the analysis, and section 4 provides the results of different model specifications. Section 5 evaluates the predictions of the employed models, and section 6 reviews robustness checks. Section 7 concludes.

\footnotetext{
${ }^{1}$ As will be discussed in following sections, recently various extensions of zero-inflated models have been emphasised by Haris et al (2014) and are incorporated in STATA. More details about some of these models are discussed in Hilb (2011). While, STATA is not able to provide panel data estimates for zero-inflated models, LIMDEP is able to estimate fixed effect and random effect models in this context.
} 


\section{Methodology}

\subsection{Discussion of Over Dispersion}

In what follows we discuss the importance of properly accounting for over dispersion when it is present in count data models such as the ones used to model doctor and hospital visits. As Hilb (2011) discusses, omitted variable, the existence of outliers, or clustering that results in correlation between responses can cause over-dispersion. Its presence in count data models raises the Pearson statistics adjusted with degree of freedom above one ${ }^{2}$. The uncontrolled over-dispersion may results in unreliable hypothesis test. In what follows we present how over-dispersion can be taken into account for count data models through mixing the Poisson distribution with other distributions.

\subsection{Count data models}

A Poisson model with equal mean and variance, $E\left(Y_{i}\right)=V\left(Y_{i}\right)=\mu_{i}$, has no power in dealing with over-dispersion. To make it more flexible, the model can be augmented with other distributions. This is done by relating its mean to an individual unobserved effect $\left(u_{i}\right)$. We can obtain different extensions of the Poisson model depending on how we specify the distribution for $u_{i}$. Appendix B, Table B1, provides an extensive discussion about these extensions. A Generalized Poisson (GP) model can also accommodate both over-dispersion and under-dispersion. We use these distributions to discuss the robustness of the results in the analysed data.

\subsection{Zero-inflated count models}

Data with more zeros than what we expect from a particular distribution may be a suspect of overdispersion. Zero-inflated Poisson (ZIP) model and zero-inflated negative binomial (ZINB) models adjust for excessive zeros in the response. Hilbe et al (2014) discuss different versions of zero-inflated models. The mixture framework of these distributions can explain more of over-dispersion in the data.

Appendix B, Table B2, presents different zero-inflated distributions that are used as robustness checks for our analysis. Following Hilbe (2011), a Vuong (1989) test ${ }^{3}$ for non-nested models is used to compare the suitability of a zero-inflated distribution against its standard distribution as in Table B1. If Vuong test

\footnotetext{
${ }^{2}$ See Hilb, 2011, chapter 12.

${ }^{3}$ Vuong test is a likelihood ratio based test for selecting a specific model among non-nested models.
} 
is positive and significant, the zero-inflated model is preferred to its corresponding standard one. With negative and significant value, the standard model is the selected one. With a non-significant Vuong test, none of them is preferred to the other one. As an additional check, we look at the predictability of different model specifications.

\section{Data description}

We use the same data as in Rephahn et al (2003) that is "the first twelve annual waves (1984 through 1995) of the German Socioeconomic Panel (GSOEP) which surveys a representative sample of East and West German households". The data set is downloadable from the web site of Journal of Applied Econometrics ${ }^{4}$. The data is restricted to individuals aged between 25 and 65. Table A1 presents the descriptive statistics of the dependent variable by gender ${ }^{5}$. Following Rephahn et al (2003), the dependent variables are defined as "the number of visits to a doctor within the last quarter prior to the survey, and the number of inpatient hospital visits with at least one night spent in the hospital within a given calendar year".

Table 1 shows the presence of inflated-zeros in both hospital visits and doctor visits for both genders. Around $92 \%$ and $44 \%$ of males did not visit a hospital and a doctor. For females, the shares of zero hospital and doctor visit are around $90 \%$ and 30\%, respectively. The abundance of zeros in both kinds of visits suggests that zero-inflated distributions might be better options rather than their standard versions for the purpose of examining doctor and hospital demands. Since the frequency of zeros for doctor visits is less than for hospital visits, this paper focuses on the demand equation for doctor visits. If the results for this equation confirm the superiority of zero-inflated distributions over their standard versions, the results can be extended to demand for hospital visits as well. Among the explanatory variables, Rephahn et al (2003) consider two different dummy variables for two types of insurance: whether an individual has public insurance or not, and, if yes whether he or she has an add-on insurance policy, which is an optional policy to cover some other costs. They argue that $90 \%$ of German people have mandatory insurance policy with only $1 \%$ without any insurance.

All the explanatory variables are the same as Rephahn et al (2003); see table A1 in the appendix.

\footnotetext{
${ }^{4}$ See: http://qed.econ.queensu.ca/jae/

${ }^{5}$ For more detail about the data see Table A1 in the appendix as well as Rephahn et al (2003).
} 
Table 1: Dependent variables: Descriptive statistics

\begin{tabular}{|c|c|c|c|c|}
\hline \multirow[b]{3}{*}{ Value } & \multicolumn{4}{|c|}{ (Share of total observation, \%) } \\
\hline & \multicolumn{2}{|c|}{ Hospital visit } & \multicolumn{2}{|c|}{ Doctor Visit } \\
\hline & "Males & Females & "Males & Females \\
\hline 0 & 92.21 & 90.18 & 44.05 & 29.51 \\
\hline 1 & 6.18 & 7.88 & 13.82 & 13.17 \\
\hline 2 & 1.09 & 1.28 & 11.63 & 13.42 \\
\hline 3 & 0.15 & 0.27 & 8.48 & 11.49 \\
\hline 04-Sep & 0.21 & 0.25 & 15.29 & 21.83 \\
\hline 10 and more & 0.16 & 0.14 & 6.73 & 10.58 \\
\hline Mean & 0.128 & 0.15 & 2.63 & 3.79 \\
\hline Std dev. & 0.93 & 0.83 & 5.21 & 6.11 \\
\hline Median & 0 & 0 & 1 & 2 \\
\hline $\mathrm{N}$ & 14243 & 13083 & 14243 & 13083 \\
\hline
\end{tabular}

Source, German Socioeconomic Panel (1984-1995)

\section{Discussion of the Results}

\subsection{Panel Data Models}

On the demand side, Rephahn et al (2003) assume a bivariate model for the demands of doctor and hospital visits. These demands follow a Poisson distribution, and the unobservable heterogeneity and error terms follow lognormal and bivariate normal distributions, respectively:

$$
\begin{gathered}
y_{i t g} \sim P o\left(\mu_{i t g}\right) \quad g=1,2 \text { (with } 1 \text { for doctor visits and } 2 \text { for hospital visits) } \\
\ln \left(\mu_{i t 1}\right)=\beta^{\prime} x_{i t 1}+u_{i 1}+\varepsilon_{i t 1} ; u_{i 1} \sim N\left(0, \sigma_{u 1}^{2}\right) ;\left(\varepsilon_{i t 1}, \varepsilon_{i t 2}\right) \sim N_{2}\left(0,0, \sigma_{\varepsilon 1}^{2}, \sigma_{\varepsilon 2}^{2}, \rho\right) ; E\left[u_{i g} u_{j h}\right)=0 \text { if } i \neq \\
j \vee g \neq h \\
\ln \left(\mu_{i t 2}\right)=\beta^{\prime} x_{i t 2}+u_{i 2}+\varepsilon_{i t 2} ; u_{i 2} \sim N\left(0, \sigma_{u 2}^{2}\right) ; E\left[\varepsilon_{i t g} u_{j h}\right)=0 \quad \forall i, t, g, j, h ; E\left[\varepsilon_{i t g} \varepsilon_{j s h}\right)=0 \quad \text { if } t \neq \\
s i \neq j \vee g \neq h
\end{gathered}
$$

To integrate out the unobserved heterogeneity $u_{i g}$, a Gauss- Hermite approximation was used, while to integrate the distribution of cross-equation errors $\left(\varepsilon_{i t g}\right)$ a modified Gauss-Legendre approach was applied.

Rephahn et al (2003) use the public insurance dummy to check for moral hazard and the add-on insurance dummy to check for adverse selection. The results indicate no evidence of moral hazard for demands for doctor visits and hospital visits: the coefficient of public insurance dummy are statistically insignificant and negative for male’s hospital demand. Their model estimates positive coefficients for addons for both demands, though it is statistically significant only for males' hospital demand and confirming 
adverse selection for it. Also they found that self-employed females and males have fewer visits to doctors than other employees.

\subsection{Random effects model}

As mentioned above, Riphahn Overall (2003) do control for unobserved effects by mixing Poisson distributions, however, their model lacks accounting for the inflated zeros in the data. Consequently, by taking into account this issue one can provide more reliable estimated parameters for add-on and public insurance variables.

To reconcile our analysis with Rephahn et al (2003), we first estimate random effects models for doctor visits using a Gaussian distribution and a Gamma distribution to account for the unobserved heterogeneity. For the purpose of comparing our model with their model, we focus on the estimated coefficients for public insurance and add-on insurance dummies.

Table 2 reports the doctor visits' results for both females and males. Based on AIC and BIC criteria, we see that Gamma distribution is a better choice for the data. Also, with Gamma distribution the coefficient of public insurance is positive and statistically significant for both females and males while in the case of Gaussian distribution both of them are positive but insignificant. For both models, the coefficient of add-on is negative but not significant. The results show that, although it seems that Gaussian distribution is more flexible than Gamma, NB2 (a mixture of Poisson and Gamma) is a better option for this data.

Table 2: Random effect model with Gaussian and Gamma distributions for the unobserved heterogeneity term

\begin{tabular}{|c|c|c|c|c|}
\hline & \multicolumn{2}{|c|}{ Males } & \multicolumn{2}{|c|}{ Females } \\
\hline & RE Normal & RE Gamma & RE Normal & RE Gamma \\
\hline \multicolumn{5}{|l|}{ Doctor visit equation } \\
\hline \multirow[t]{2}{*}{ Public Insurance } & 0.106 & $0.103^{* * *}$ & 0.0638 & $0.0690^{*}$ \\
\hline & $(0.0844)$ & $(0.0388)$ & $(0.0733)$ & $(0.0360)$ \\
\hline \multirow[t]{2}{*}{ Add-on Insurance } & -0.0334 & -0.0340 & -0.0260 & -0.0317 \\
\hline & $(0.103)$ & $(0.0535)$ & $(0.0897)$ & $(0.0456)$ \\
\hline \multirow[t]{2}{*}{ Lnsig2u } & 0.0138 & & $-0.248^{* * *}$ & \\
\hline & $(0.0393)$ & & $(0.0391)$ & \\
\hline \multirow[t]{2}{*}{ Lnalpha } & & -0.00860 & & $-0.277^{* * *}$ \\
\hline & & $(0.0293)$ & & $(0.0286)$ \\
\hline Observations & 14243 & 14243 & 13083 & 13083 \\
\hline AIC & 65802.1774 & 65713.7349 & 70856.0950 & 70728.1257 \\
\hline$B I C$ & 65976.1498 & 65887.7074 & 71028.1136 & 70900.1443 \\
\hline Log lik. & -32878.1 & -32833.9 & -35405.0 & -35341.1 \\
\hline
\end{tabular}

Standard errors in parentheses

Source, German Socioeconomic Panel (1984-1995)

${ }^{*} p<0.10,{ }^{* *} p<0.05,{ }^{* * *} p<0.01$ 


\subsection{Standard count models:}

Following Greene (2008), we use pooled data to select the best model between standard models. Table 3 presents the results for males’ visits to doctors when employing the models in Table B1: Poisson, Negative Binomial 1 (NB1), Negative Binomial 2 (NB2), Generalized Poisson (GPoisson), Negative Binomial Famoye (NB Famoye), and Negative Binomial Waring (NB Waring).

Table 3: Standard Distributions for Doctor Visit for males

\begin{tabular}{|c|c|c|c|c|c|c|}
\hline & Poisson & NB1 & NB2 & Gen Possion & NBFamoy & GNBWaring \\
\hline \multicolumn{7}{|l|}{ Doctor visit equation } \\
\hline Public Insurance & $\begin{array}{l}0.100 \\
(0.0702)\end{array}$ & $\begin{array}{l}0.0607 \\
(0.0539)\end{array}$ & $\begin{array}{l}0.0934 \\
(0.0635)\end{array}$ & $\begin{array}{l}0.0595 \\
(0.0549)\end{array}$ & $\begin{array}{l}0.0934 \\
(0.0635)\end{array}$ & $\begin{array}{l}0.0578 \\
(0.0577)\end{array}$ \\
\hline Add-on Insurance & $\begin{array}{l}0.0666 \\
(0.102)\end{array}$ & $\begin{array}{l}0.139^{*} \\
(0.0777)\end{array}$ & $\begin{array}{l}0.0551 \\
(0.0948)\end{array}$ & $\begin{array}{l}0.144^{*} \\
(0.0791)\end{array}$ & $\begin{array}{l}0.0551 \\
(0.0948)\end{array}$ & $\begin{array}{l}0.154^{*} \\
(0.0844)\end{array}$ \\
\hline Constant & $\begin{array}{l}2.771^{* * *} \\
(0.336)\end{array}$ & $\begin{array}{l}2.776^{* * *} \\
(0.254)\end{array}$ & $\begin{array}{l}3.149^{* * *} \\
(0.329)\end{array}$ & $\begin{array}{l}2.780^{* * *} \\
(0.258)\end{array}$ & $\begin{array}{l}3.710^{* * *} \\
(0.330)\end{array}$ & $\begin{array}{l}2.929^{* * *} \\
(0.273)\end{array}$ \\
\hline Lndelta & & $\begin{array}{l}1.581^{* * * *} \\
(0.0365)\end{array}$ & & & & \\
\hline Lnalpha & & & $\begin{array}{l}0.561^{* * *} \\
(0.0270)\end{array}$ & & & \\
\hline Atanhdelta & & & & $\begin{array}{l}0.726^{* * *} \\
(0.0115)\end{array}$ & & \\
\hline Lnphim1 & & & & & $\begin{array}{l}-17.76^{* * *} \\
(3.253)\end{array}$ & \\
\hline Lntheta & & & & & $\begin{array}{l}-0.561^{* * *} \\
(0.0270)\end{array}$ & \\
\hline Lnrhom2 & & & & & & $\begin{array}{l}0.783^{* * *} \\
(0.0981)\end{array}$ \\
\hline Lnk & & & & & & $\begin{array}{l}2.303^{* * *} \\
(0.130)\end{array}$ \\
\hline Observations & 14243 & 14243 & 14243 & 14243 & 14243 & 14243 \\
\hline$A I C$ & 85593.4779 & 54865.9120 & 55006.8616 & 54700.9022 & 55008.8616 & 54528.6162 \\
\hline BIC & 85759.8863 & 55039.8845 & 55180.8341 & 54874.8747 & 55190.3981 & 54710.1527 \\
\hline Log lik. & -42774.7 & -27410.0 & -27480.4 & -27327.5 & -27480.4 & -27240.3 \\
\hline Dispersion & 6.67597 & constant & 1.998817 & & & \\
\hline
\end{tabular}

Source, German Socioeconomic Panel (1984-1995)

${ }^{*} p<0.10,{ }^{* *} p<0.05,{ }^{* * *} p<0.01$

The results for Poisson, NB1 and NB2 are the same as in Greene (2008). Based on the dispersion criteria which has a high dispersion value of 6.67, Poisson distribution is not suitable. NB2 defeats Poisson by reducing considerably the value of dispersion to 1.99 . This can also be confirmed by $\ln (\alpha)=0.561$ which measures the logarithm of the dispersion parameter $(\alpha)$ and based on the likelihood ratio test is statistically significant. The same conclusion is obtained for other distribution: NB1, Generalized Poisson, NB Famoye and NB. Using AIC and BIC criteria, the NB Waring model is the best model for these data. It is followed by the Generalized Poisson, NB1, NB2, and NB Famoye. 
NB Waring model estimates a positive and significant coefficient for the add-on insurance. In addition this parameter is positive in all models but only significant in NB1 and Generalized Poisson and NB Waring models. The estimated parameter for public insurance is positive in all the models but statistically insignificant. Table A2 in the appendix A reports all parameter estimates.

Table A3 in the appendix A, shows the same results for females. The results for dispersion and the ranking of the best models are the same as for males. Still, NB Waring is the best one and NB2 is in the second rank. The only difference is observed in add-on's estimated parameter. This parameter is positive, and, as for males, statistically significant for NB1 and generalized Poisson but not for NB Waring. For public insurance, all the models provide positive values except for the Poisson model, which is a completely unreliable model, where it is statistically significant. This can be viewed as evidence of overdispersion, leading to underestimation of standard errors, making the coefficient statistically significant.

To conclude this analysis, we can state that even if we ignore the zero-inflated nature of the data, we can designate NB family and Generalized Poisson as better choices than the simple Poisson model.

Finally, Table 4 provides results for heterogeneous NB2. For this model, all the explanatory variables are used to explain its dispersion parameter. In comparison, AIC and BIC criteria indicates that this model is better than the simple Poisson for both males and females. Also, based on AIC criteria, this model has the lowest value compared to other specifications. In this model only the coefficient of public insurance for females is statistically significant.

Table 4: Heterogeneous NB2 for Doctor Visit for Males and Females

\begin{tabular}{lll}
\hline & Hete NB2 Male & Hete NB2 Female \\
\hline Doctor visit equation & 0.0940 & $0.105^{*}$ \\
Public Insurance & $(0.0652)$ & $(0.0599)$ \\
& 0.0427 & 0.0347 \\
Add-on Insurance & $(0.0927)$ & $(0.0754)$ \\
& $2.977^{* * *}$ & $2.874^{* * *}$ \\
Constant & $(0.318)$ & $(0.272)$ \\
\hline Lnalpha & 0.0188 & 0.0190 \\
Public Insurance & $(0.0985)$ & $(0.102)$ \\
& $-0.397^{* * *}$ & $-0.495^{* * *}$ \\
Add-on Insurance & $(0.153)$ & $(0.142)$ \\
& $-0.839^{*}$ & $-1.217^{* * *}$ \\
Constant & $(0.452)$ & $(0.453)$ \\
\hline Observations & 14243 & 13083 \\
AIC & 54493.3321 & 60278.6270 \\
BIC & 54826.1490 & 60607.7061 \\
Log lik. & -27202.7 & -30095.3 \\
\hline
\end{tabular}

Source, German Socioeconomic Panel (1984-1995)

${ }^{*} p<0.10,{ }^{* *} p<0.05,{ }^{* * *} p<0.01$ 


\subsection{Zero-inflated models (Pooled data)}

Following Greene (2008) again, we use pooled data to select the best model among zero-inflated models introduced in Table B2. Since for the zero inflated models it is necessary to specify the inflation function, all the explanatory variables are covariates in this function.

Table 5 provides estimation results related to zero-inflated models for males. Based on the positive and statistically significant values of Vuong statistics (the test for non-nested models), there is a strong evidence to prefer the zero-inflated models to their corresponding standard models. Also, add-on contributes to the over-dispersion in the data as it is significant in the zero-inflated function. The ZeroInflated Negative Binomial (ZINB) Waring model has the lowest AIC and BIC values followed by ZINB2 ZINB-Famoye and zero-Inflated Poisson (ZIP). The statistically significant estimated parameters related to dispersion in ZINB Waring and ZINB2 indicate that zero-inflated Poisson is not a good choice for these data and its significant coefficient for add-on is not reliable.

Table 5: Zero-Inflated Models for Males

\begin{tabular}{|c|c|c|c|c|}
\hline & ZIP & ZINB2 & ZINBFamoye & ZINBWaring \\
\hline \multicolumn{5}{|l|}{ Doctor visit equation } \\
\hline Public Insurance & $\begin{array}{l}0.0794^{* * *} \\
(0.0247)\end{array}$ & $\begin{array}{l}0.0971^{*} \\
(0.0571)\end{array}$ & $\begin{array}{l}0.0899 \\
(0.0560)\end{array}$ & $\begin{array}{l}0.0565 \\
(0.0623)\end{array}$ \\
\hline \multirow[t]{2}{*}{ Add-on Insurance } & $-0.0839^{*}$ & -0.0388 & -0.0694 & -0.00574 \\
\hline & $(0.0430)$ & $(0.0962)$ & $(0.0933)$ & $(0.101)$ \\
\hline \multirow[t]{2}{*}{ Constant } & $2.502^{* * *}$ & $2.567^{* * *}$ & -5.078 & $2.598^{* * *}$ \\
\hline & $(0.108)$ & $(0.263)$ & $(154.3)$ & $(0.291)$ \\
\hline \multicolumn{5}{|l|}{ Inflate Equation } \\
\hline Public Insurance & $\begin{array}{l}-0.0226 \\
(0.0755)\end{array}$ & $\begin{array}{l}0.0342 \\
(0.162)\end{array}$ & $\begin{array}{l}0.00727 \\
(0.124)\end{array}$ & $\begin{array}{l}-0.00330 \\
(0.148)\end{array}$ \\
\hline \multirow[t]{2}{*}{ Add-on Insurance } & $-0.423^{* * *}$ & -0.651 & $-0.590^{*}$ & $-0.637^{*}$ \\
\hline & $(0.157)$ & $(0.446)$ & $(0.316)$ & $(0.387)$ \\
\hline \multirow[t]{2}{*}{ Constant } & $-3.718^{* * *}$ & $-6.989^{* * *}$ & $-5.710^{* * *}$ & $-4.933^{* * *}$ \\
\hline & $(0.371)$ & $(0.935)$ & $(0.670)$ & $(0.772)$ \\
\hline Lnalpha & & $\begin{array}{l}0.154^{* * *} \\
(0.0303)\end{array}$ & & \\
\hline Lnphim1 & & & $\begin{array}{l}6.560 \\
(154.4)\end{array}$ & \\
\hline Lntheta & & & $\begin{array}{l}7.652 \\
(154.3)\end{array}$ & \\
\hline Lnrhom2 & & & & $\begin{array}{l}0.866^{* * *} \\
(0.0550)\end{array}$ \\
\hline Constant & & & & $0.897^{* * *}$ \\
\hline & & & & $(0.103)$ \\
\hline Observations & 14243 & 14243 & 14243 & 14243 \\
\hline AIC & 70905.8533 & 54536.9885 & 54383.8199 & 54168.3164 \\
\hline BIC & 71238.6702 & 54877.3694 & 54731.7649 & 54516.2613 \\
\hline Log lik. & -35408.9 & -27223.5 & -27145.9 & -27038.2 \\
\hline Vuong statistic & $31.546871^{* * *}$ & $11.554577^{* * *}$ & $14.015931^{* * *}$ & $21.082627^{* * *}$ \\
\hline
\end{tabular}

Standard errors in parentheses

Source, German Socioeconomic Panel (1984-1995)

${ }^{*} p<0.10,{ }^{* *} p<0.05,{ }^{* * *} p<0.01$ 
The estimated parameters for add-on are negative for all of the models but statistically insignificant except for ZIP. Moreover, the public insurance coefficient is positive and statistically significant ZIP and ZINB2.

Table 6 provides the results of zero-inflated models for females. The results for females are similar to those for males. In the case of females, the coefficient for public insurance is statistically positive for ZINB2 model.

Table 6: Zero-Inflated Models for Females

\begin{tabular}{|c|c|c|c|c|}
\hline & ZIP & ZINB2 & ZINBFamoy & ZINBWaring \\
\hline \multicolumn{5}{|l|}{ Doctor visit equation } \\
\hline \multirow[t]{2}{*}{ Public Insurance } & $0.112^{* * *}$ & $0.0788^{*}$ & 0.0674 & 0.0595 \\
\hline & $(0.0217)$ & $(0.0466)$ & $(0.0459)$ & $(0.0495)$ \\
\hline \multirow[t]{2}{*}{ Add-on Insurance } & $-0.0652^{*}$ & -0.0146 & -0.0333 & 0.0649 \\
\hline & $(0.0337)$ & $(0.0768)$ & $(0.0758)$ & $(0.0753)$ \\
\hline \multirow[t]{2}{*}{ Constant } & $2.307^{* * *}$ & $2.586^{* * *}$ & -5.259 & $2.663^{* * *}$ \\
\hline & $(0.0922)$ & $(0.222)$ & (134.6) & $(0.228)$ \\
\hline \multicolumn{5}{|l|}{ Inflate Equation } \\
\hline \multirow[t]{2}{*}{ Public Insurance } & -0.0857 & -0.207 & -0.149 & -0.122 \\
\hline & $(0.0855)$ & $(0.194)$ & $(0.145)$ & $(0.165)$ \\
\hline \multirow[t]{2}{*}{ Add-on Insurance } & $-0.427^{* *}$ & -0.913 & -0.733 & -0.459 \\
\hline & $(0.176)$ & $(0.887)$ & $(0.476)$ & $(0.416)$ \\
\hline \multirow[t]{2}{*}{ Constant } & $-4.329^{* * *}$ & $-8.360^{* * *}$ & $-6.726^{* * *}$ & $-5.556^{* * *}$ \\
\hline & $(0.417)$ & (1.218) & $(0.829)$ & $(0.883)$ \\
\hline Lnalpha & & $\begin{array}{c}-0.0723^{* * *} \\
(0.0258)\end{array}$ & & \\
\hline \multirow[t]{2}{*}{ Lnphim1 } & & & 6.579 & \\
\hline & & & (134.7) & \\
\hline \multirow[t]{2}{*}{ Lntheta } & & & 7.879 & \\
\hline & & & (134.6) & \\
\hline \multirow[t]{2}{*}{ Lnrhom2 } & & & & $1.091^{* * *}$ \\
\hline & & & & $(0.0464)$ \\
\hline \multirow{2}{*}{ Lnk } & & & & $1.142^{* * *}$ \\
\hline & & & & $(0.0868)$ \\
\hline Observations & 13083 & 13083 & 13083 & 13083 \\
\hline AIC & 79784.3595 & 60296.0349 & 60130.3157 & 59863.0979 \\
\hline BIC & 80113.4386 & 60632.5930 & 60474.3529 & 60207.1351 \\
\hline Log lik. & -39848.2 & -30103.0 & -30019.2 & -29885.5 \\
\hline Vuong_statistic & $31.52^{* * *}$ & $8.80^{* * *}$ & $12.18^{* * *}$ & $12.67^{* * *}$ \\
\hline
\end{tabular}

Standard errors in parentheses

Source, German Socioeconomic Panel (1984-1995)

${ }^{*} p<0.10,{ }^{* *} p<0.05,{ }^{* * *} p<0.01$ 


\section{Model Evaluation}

\subsection{Distribution comparisons}

In this section, we compare the predictions of Poisson, zero-inflated Poisson (ZIP), NB2, and ZINB2 for doctor's visit with the corresponding actual distribution ${ }^{6}$. Figure $1 \mathrm{a}$ and Figure $1 \mathrm{~b}$ compare the predicted frequency of the number of doctor visits by Poisson and ZIP with their actual frequencies. Both figures show that Poisson and zero-inflated Poisson models underestimate the zeros and overestimate the ones. Figure 1c compares the distributions results from the Poisson and zero-inflated Poisson models. We see that zero-inflated Poisson increases the estimated frequency of zeros by almost $40 \%$, which is a substantial improvement in terms of prediction. We observe also some improvements in the reduction of the estimated one and two visits. Regarding four and more visits, both models are nearly the same.

Figures 1c, 1d and 1e compare the results for NB2 and zero-inflated NB2. The improvement in the number of zeros using zero-inflated NB2 is almost $20 \%$ compared with the standard NB2. This improvement is less than what we mentioned above comparing Poisson and zero-inflated Poisson. We can justify it since comparing with Poisson model the standard NB2 has more power in accounting for overdispersion, as we discussed before. This can also be seen in Tables A4 to A7 of the appendix A. For example, standard Poisson distribution predicts correctly 838 zeros while standard NB2 predicts correctly 1170 zeros. With zero-inflated Poisson and zero-inflated NB2 these values increase to 1441 and 1446, respectively. In addition, the zero-inflated models provide some improvements on the estimation of other numbers of doctor visits.

\footnotetext{
${ }^{6}$ Since the predicted values might not be integers, we convert them to the closest integer.
} 
Figure 1: Doctor visits (DV) and predicted DV by model specification
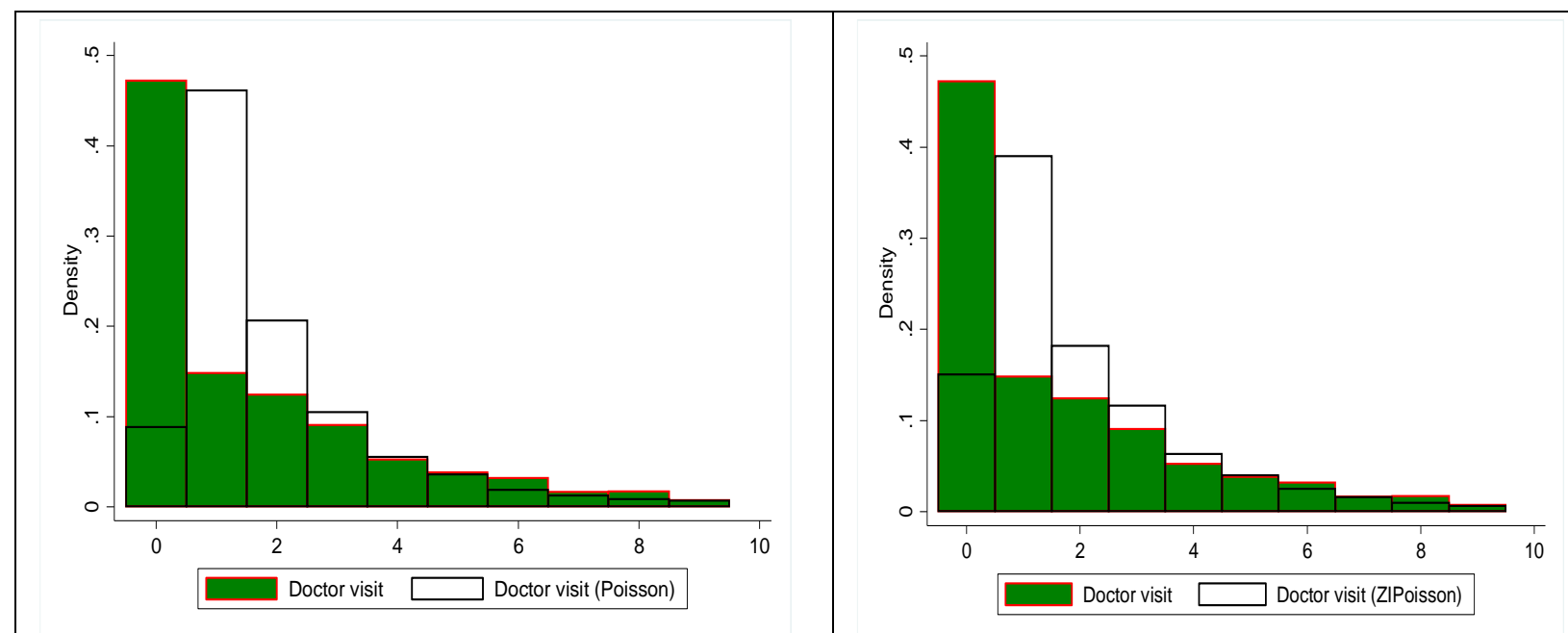

Figure1a: Doctor visits (DV) and predicted DV (by

Figure 1b: DV and predicted DV (by ZIPoisson) Poisson)

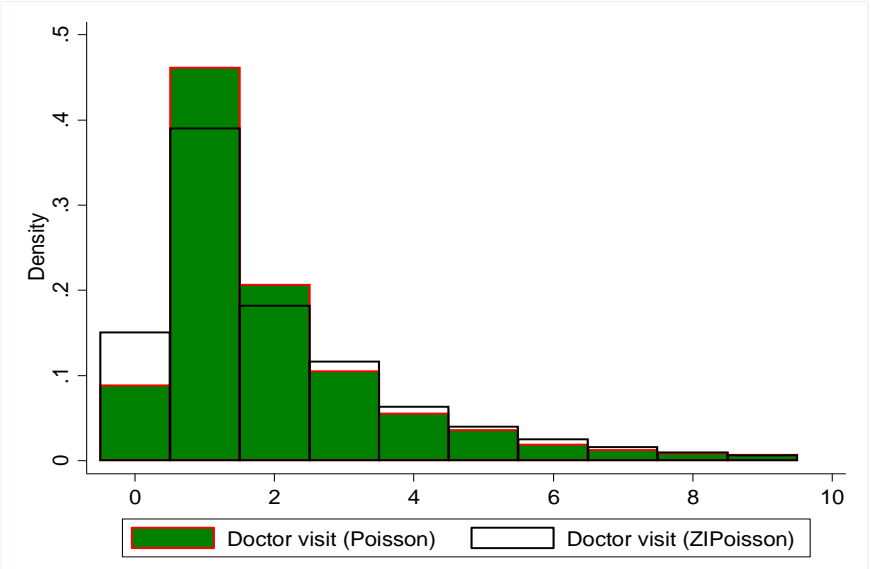

Figure 1c: Predicted DV by Poisson and ZIPoisson 

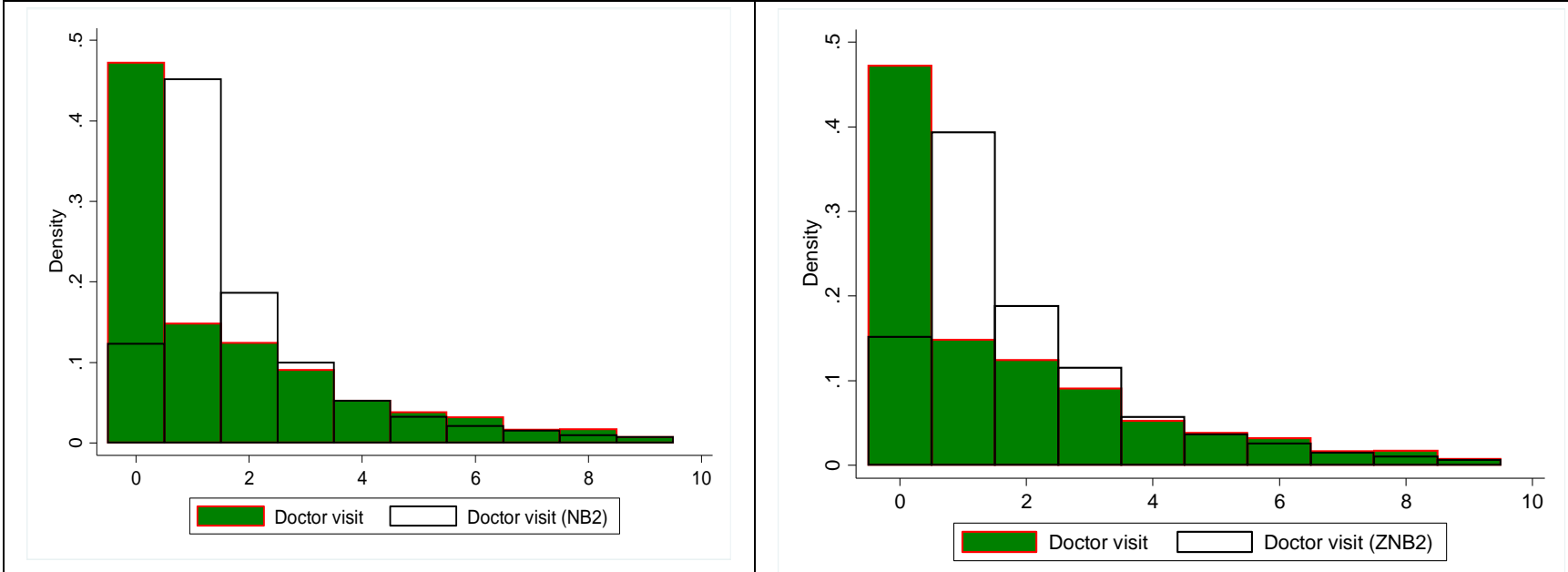

Figure 1d: DV and predicted DV (by NB2)

Figure 1e: DV and predicted DV (by ZNB2)

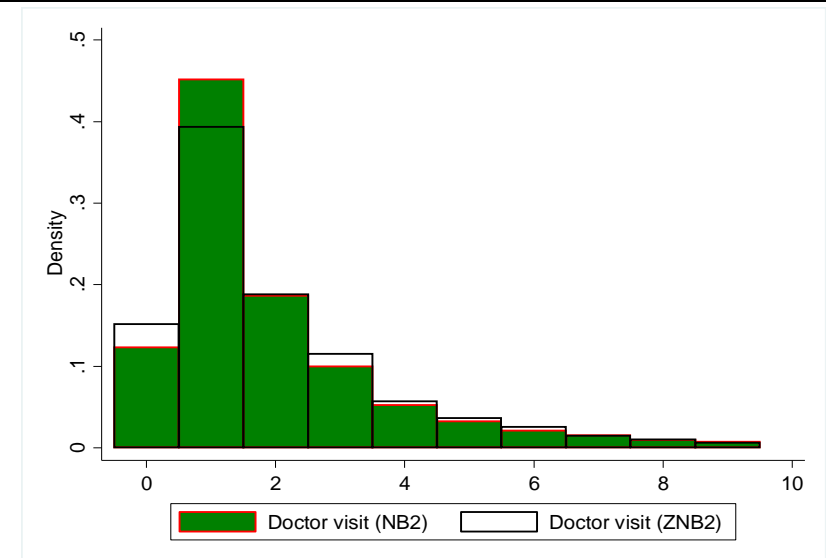

Figure 1f: Predicted DV by NB2 and ZNB2

\subsection{Predicted versus realizations comparisons}

Table 7 compares four models based on the maximum differences and mean absolute differences between predicted and actual counts. The results show that Poisson performs worst at predicting the 0s, and NB2 and ZIP perform worst at predicting the 1s, while ZINB2 is worst at predicting the 2s. However, the maximum difference and mean of absolute differences are much lower for ZINB2 which means this model is the best one in terms of overall prediction. The Pearson statistic equals 193.429 for this model (the lowest of all models), which confirms it is the best model in terms of prediction (see table A8 in the appendix A for more details). 


\section{Table 7: Comparing the mean of observed and predicted count}

\begin{tabular}{cccc}
\hline Model & $\begin{array}{c}\text { Maximum } \\
\text { Difference }\end{array}$ & At Value & $\begin{array}{c}\text { Mean } \\
\mid \text { Diff } \mid\end{array}$ \\
\hline Poisson & 0.273 & 0 & 0.054 \\
NB2 & -0.042 & 1 & 0.009 \\
ZIP & 0.082 & 1 & 0.023 \\
ZINB2 & 0.017 & 2 & 0.006 \\
\hline
\end{tabular}

Figure 2 presents the density comparison between actual and predicted probabilities. Again, we see that ZINB2 is superior to ZIP in predicting actual probabilities. Further, Figure 3 plots the residuals from the tested models. Small residuals indicate a good fit, so the models with lines closest to zero should be considered as the suitable ones. We can see that the residuals line for ZINB2 is very close to zero when compared with the line of residuals for all the other models, confirming the results of all previous findings.

Figure 2: Density comparison between actual and predicted probabilities
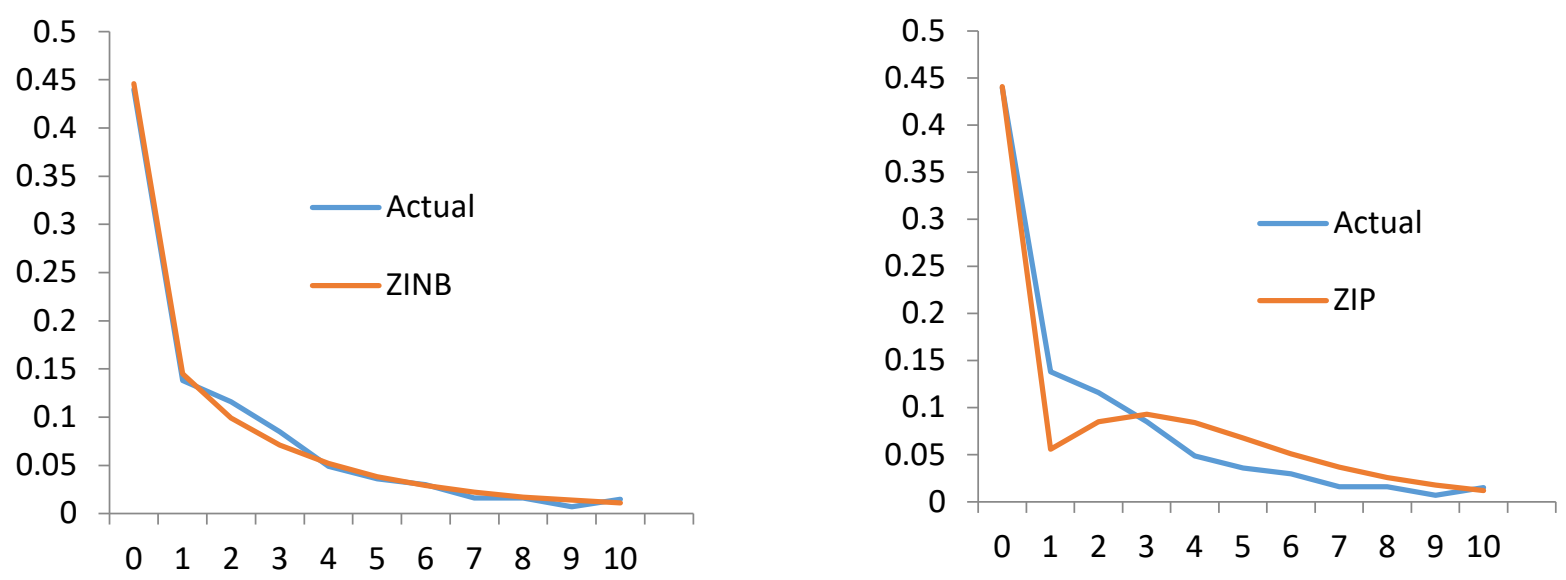

Actual probabilities versus Zero Inflated Negative Actual probabilities versus Zero Inflated Poisson Binomial 
Figure 3: Residual plots of PRM(Poisson Random Effect Model, NBRM (NB Random Effect Model), ZIP(Zero Inflated Poisson Model), ZINB(Zero Inflated NB Model)

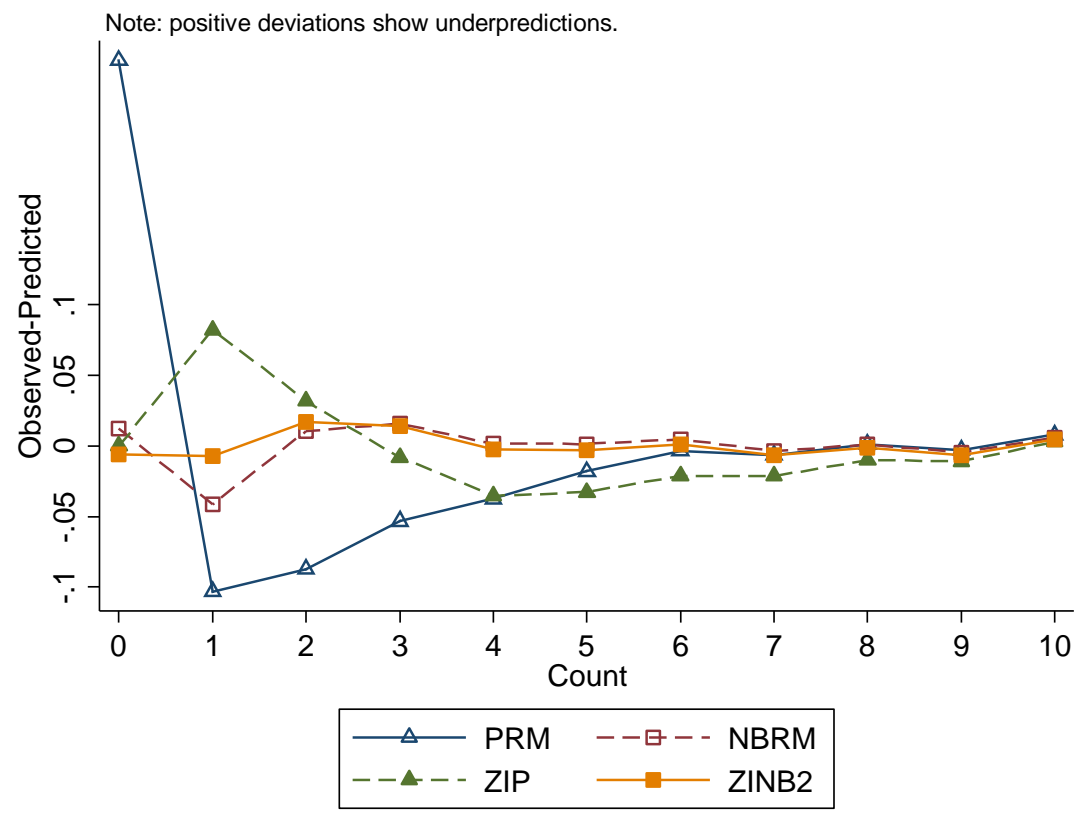

Finally, Table 8 provides tests for choosing the best model in terms of fit statistics such as AIC and BIC as well as Vuong statistic. The results also indicate that ZINB2 is the best model among the models under consideration.

Table 8: Tests of fit statistics

\begin{tabular}{|c|c|c|c|c|c|}
\hline Poisson & BIC $=85759.8$ & AIC $=85593.5$ & Prefer & Over & Evidence \\
\hline \multirow[t]{3}{*}{ Vs NB2 } & $\mathrm{BIC}=55180.8$ & Diff $=30579.1$ & NB2 & Poisson & Very strong \\
\hline & $\mathrm{AIC}=55006.8$ & Diff $=30586.6$ & NB2 & Poisson & \\
\hline & LRX2=30588.6 & Prob $=0.000$ & NB2 & Poisson & $\mathrm{P}=0.000$ \\
\hline \multirow[t]{3}{*}{ Vs ZIP } & $\mathrm{BIC}=71238.7$ & Diff $=14521.2$ & ZIP & Poisson & Very strong \\
\hline & $\mathrm{AIC}=70905.8$ & Diff $=14687.6$ & ZIP & Poisson & \\
\hline & Vuong $=31.54$ & Prob $=0.000$ & ZIP & Poisson & $\mathrm{P}=0.000$ \\
\hline \multirow[t]{2}{*}{ Vs ZINB2 } & $\mathrm{BIC}=54877.4$ & Diff $=30882.5$ & ZINB & Poisson & Very strong \\
\hline & $\mathrm{AIC}=54536.9$ & Diff $=31056.5$ & ZINB & Poisson & \\
\hline NB2 & $B I C=55180.8$ & AIC $=55006.8$ & Prefer & Over & Evidence \\
\hline \multirow[t]{2}{*}{ Vs ZIP } & $\mathrm{BIC}=71238.7$ & Diff $=-16057.8$ & NB2 & ZIP & Very strong \\
\hline & $\mathrm{AIC}=70905.8$ & Diff $=-15898.9$ & NB2 & ZIP & \\
\hline \multirow[t]{3}{*}{ Vs ZINB2 } & $\mathrm{BIC}=54877.4$ & Diff $=303.4$ & ZINB2 & NB2 & Very strong \\
\hline & $\mathrm{AIC}=54536.9$ & Diff $=469.8$ & ZINB2 & NB2 & \\
\hline & Vuong=11.55 & Prob $=0.000$ & ZINB2 & NB2 & $\mathrm{P}=0.000$ \\
\hline ZIP & $\mathrm{BIC}=71238.7$ & AIC $=70905.8$ & Prefer & Over & Evidence \\
\hline \multirow[t]{3}{*}{ Vs ZINB2 } & $\mathrm{BIC}=54877.4$ & Diff $=16361.3$ & ZINB2 & ZIP & Very strong \\
\hline & $\mathrm{AIC}=54536.9$ & Diff $=16368.8$ & ZINB2 & ZIP & \\
\hline & LRX2 $=16370.8$ & Prob $=0.000$ & ZINB2 & ZIP & $\mathrm{P}=0.000$ \\
\hline
\end{tabular}




\section{Robustness Checks}

\subsection{Robustness results on pooled sample}

The results of previous sections show that zero-inflated NB2 could be considered a suitable model in terms of prediction for both female and male subsamples. The model predicts that public insurance has a positive and statistically significant coefficient for both subsamples, which has implications on the income effects of individuals.

Now, we check if we can get the same results as before by pooling males and females data. We add a dummy variable with value of 1 for females and value of 0 for males to the explanatory variables. Consequently, six different models for the whole sample are estimated: Poisson with Gaussian random effect, Poisson with Gamma random effect, NB2, NB Waring, zero-inflated NB2 as well as zero-inflated NB Waring.

Table 9 reports the estimation results for the six models. In all of them the estimated coefficients for females are positive and statistically different from zero which confirms our focusing on two separate samples for males and females in the previous sections. It also means that on average, ceteris paribus; females will demand more visits for doctors than males. Between the random effect models, the one with Gamma distribution for the unobserved heterogeneity performs best (both AIC and BIC are predicting the same result). However, all the pooled data models are preferred to random-effect models. Further, the Voung statistic used to compare non-nested models is positive and statistically significant for the zeroinflated models, meaning that zero-inflated models provide better predictions than their standard counterparts. Furthermore, based on AIC and BIC, the zero-inflated Waring model, though less accurate in convergence, is preferred to the zero-inflated NB2. Finally, all the models estimate a positive coefficient for public insurance and are statistically significant except for the Gaussian random effect model. The results confirms the existence of moral hazard. 
Table 9: Full sample results

\begin{tabular}{|c|c|c|c|c|c|c|}
\hline & Gaussian RE & Gamma RE & NB2 & NBW & ZINB2 & ZINB \\
\hline \multicolumn{7}{|l|}{ Doctor visit equation } \\
\hline Female & $\begin{array}{l}\mathbf{0 . 3 7 7}^{* * *} \\
(0.0291)\end{array}$ & $\begin{array}{l}\mathbf{0 . 3 0 4}^{* * *} \\
(0.0244)\end{array}$ & $\begin{array}{l}\mathbf{0 . 3 5 4}^{* * *} \\
(0.0279)\end{array}$ & $\begin{array}{l}\mathbf{0 . 3 6 4} 4^{* * *} \\
(0.0234)\end{array}$ & $\begin{array}{l}\mathbf{0 . 1 8 3}^{* * *} \\
(0.0194)\end{array}$ & $\begin{array}{l}\mathbf{0 . 2 1 5} 5^{* * *} \\
(0.0207)\end{array}$ \\
\hline \multirow[t]{2}{*}{ Public Insurance } & 0.0886 & 0.0896 *** & $0.1000^{* *}$ & $0.0746 *$ & $0.0930^{* *}$ & $0.0654^{*}$ \\
\hline & $(0.0557)$ & $(0.0264)$ & $(0.0458)$ & $(0.0393)$ & $(0.0361)$ & $(0.0389)$ \\
\hline \multirow[t]{2}{*}{ Add-on Insurance } & -0.0299 & -0.0327 & 0.0497 & $0.148^{* * *}$ & -0.0193 & 0.0340 \\
\hline & $(0.0665)$ & $(0.0347)$ & $(0.0613)$ & $(0.0553)$ & $(0.0597)$ & $(0.0606)$ \\
\hline Lnsig2u & $\begin{array}{l}-0.111^{* * *} \\
(0.0277)\end{array}$ & & & & & \\
\hline Lnalpha & & $\begin{array}{l}-0.136^{* * *} \\
(0.0205)\end{array}$ & $\begin{array}{l}0.370^{* * *} \\
(0.0189)\end{array}$ & & $\begin{array}{l}0.0243 \\
(0.0195)\end{array}$ & \\
\hline Lnrhom2 & & & & $\begin{array}{l}0.842^{* * *} \\
(0.0652)\end{array}$ & & $\begin{array}{l}0.984^{* * *} \\
(0.0349)\end{array}$ \\
\hline Lnk & & & & $\begin{array}{l}2.280^{* * *} \\
(0.0923)\end{array}$ & & $\begin{array}{l}1.043^{* * *} \\
(0.0665)\end{array}$ \\
\hline \multicolumn{7}{|l|}{ Inflate equation } \\
\hline Female & & & & & $-1.216^{* * *}$ & $-0.830^{* * *}$ \\
\hline \multirow[t]{2}{*}{ Public Insurance } & & & & & -0.0469 & -0.0477 \\
\hline & & & & & $(0.120)$ & $(0.107)$ \\
\hline Add-on Insurance & & & & & $-0.682^{* *}$ & $-0.562^{* *}$ \\
\hline Observations & 27326 & 27326 & 27326 & 27326 & $\frac{(0.341)}{27326}$ & $\frac{(0.269)}{27326}$ \\
\hline AIC & 136878.2159 & 136666.2365 & 115861.5909 & 114914.2459 & 114881.7180 & 114051.5364 \\
\hline$B I C$ & 137075.3902 & 136863.4108 & 116058.7651 & 115119.6357 & 115267.8509 & 114445.8849 \\
\hline Log lik. & -68415.1 & -68309.1 & -57906.8 & -57432.1 & -57393.9 & -56977.8 \\
\hline Vuong statistic & & & & & $15.94^{* * *}$ & $39.64^{* * *}$ \\
\hline
\end{tabular}

Standard errors in parentheses

Source, German Socioeconomic Panel (1984-1995)

${ }^{*} p<0.10,{ }^{* *} p<0.05,{ }^{* * *} p<0.01$

\subsection{Accounting for correlation between doctor visits and hospital visits using the Bivariate Negative Binomial Model $^{7}$}

We also jointly estimate both doctor visits and hospital visits using a bivariate NB model to account for potential correlation between the two events. As Riphahn et al (2003) explain, doctor visits and hospital visits are positively correlated. However, this correlation should be identified and tested.

In the males sample we find a correlation between doctor visits and hospital visits of 0.1477. Using only non-zero values, this correlation reduces to 0.1138. Cameron and Trividi (2013) show how to construct a statistic for testing the independency between two counts specific regressions (for doctor visits and hospital visits). The calculated test statistic for our sample are $9.47,1.05,0.05,0.94$, respectively for $(j, k)=(1,1),(1,2),(2,1),(2,2)$. Only the first value is statistically different from zero (with p-vale equal to 0.002). This shows that independency can

7 Codes for Bivariate NB2 model are found in Cameron, C., and Trividi, P. (2013) ( see page 336) 
only be rejected for the first statistics suggesting some evidence of weak dependency between the two count variables. This is in contrast to what Riphahn et al (2003) expected. Motivated by the first test value, however, a bivariate NB2 model is estimated for males using pooled panel data (see Table 10). Here the parameter $\alpha$ can capture both overdispersion as well as correlation between unobserved heterogeneity8.

For females, the correlation between doctor visits and hospital visits for all data realizations (including the zeros) is 0.125 and when we look at only the positive values we get a correlation of 0.079. The independency test statistic for females are 38.56, 0.087, 4.81, 0.225 corresponding to $(j, k)=(1,1),(1,2),(2,1),(2,2)$, respectively. Based on the results, the first and second values of the test statistic are significant at 0.05 level. Motivated by the first two test values, a bivariate NB2 is estimated for female. The results are presented in Table 10.

We see that the $\alpha$ parameters are significant in both male and female bivariate models. This result might confirm the previous results that NB2 based models are a better distribution for explaining real data, rather than Poisson distribution. Here we find that the estimated public insurance parameters for doctor visits are positive and statistically significant for both males and females while for hospital visits are negative and insignificant. Although estimated add-on parameters are positive for all males and females in two equations, they are statistically insignificant.

Table 10: Bivariate Negative Binomial 2 for Doctor Visits and Hospital Visits

\begin{tabular}{lllll}
\hline & Males & & Females & \\
\hline \multirow{2}{*}{ Public Insurance } & Doctor visit & Hospital visit & Doctor visit & Hospital visit \\
& $0.0958^{*}$ & -0.173 & $0.105^{*}$ & -0.144 \\
Add-on Insurance & $(0.0551)$ & $(0.235)$ & $(0.0545)$ & $(0.312)$ \\
& 0.0605 & 0.550 & 0.0311 & 0.0501 \\
& $(0.0863)$ & $(0.351)$ & $(0.0648)$ & $(0.164)$ \\
\hline Alpha & $1.698^{* * *}$ & & $1.169^{* * *}$ & \\
Observations & $(0.0367)$ & & $(0.0242)$ & \\
Log Like & 14243 & & 13083 & \\
Standard errors in parentheses & -33090.1 & &
\end{tabular}

\section{Conclusion}

The high share of zeros for a dependent variable in a count data regression model can severely increase the over-dispersion issue and lead to unreliable estimators. We show that the German

\footnotetext{
${ }^{8}$ For the estimating Bivariate NB2 by ML, initial values we find by estimating non-linear seemingly unrelated regression (NLSUR) and assuming initial value for $\alpha$ equal to 2. For first stage, correlation between doctor visits and hospital visits for males and females are estimated as 0.125 and 0.078 , respectively.
} 
Socioeconomic Panel (1984-1995) used by Riphahn et al (2003) for the demand of doctor visits suffers severely from over-dispersion issue and their estimation based on standard distributions might not be reliable. Results based on standard distributions are close to Riphahn et al (2003) and, overall, there is not enough evidence for moral hazard and adverse selection except for Waring NB2, which presents a positive effect from adverse selection on the number of doctor visits. However, this result might also not be reliable due to the over-dispersion that resulted in the high share of zeros in the data. Overall we show that within the class of random effect models, the model with a Gamma distribution for unobserved heterogeneity is more suitable than the one assuming Gaussian distribution for unobserved heterogeneity.

Vuong test (1989) rejects the standard distributions in the favour of their corresponding zeroinflated distributions. This means that over-dispersion due to the high share of zeros in the data cannot be explained by any complex and/or flexible mixture of Poisson distributions such as Negative Binomial 2, Generalized Poisson, Negative Binomial Famoy, Generalized Negative Binomial Waring models. All of these are inferior to the zero-inflated distributions models. Between zero-inflated distributions, ZINB Waring model has the lowest AIC and BIC values followed by ZINB2 Famoye and ZINB2. However, when ranking the predicted probabilities, ZINB2 model produces the closest probabilities to the actual probabilities. A pooled (malefemale) sample estimation provides the same results as those obtained from subsample estimations.

In contrast to Riphahn et al (2003), most of the zero-inflated distribution models predict a negative but insignificant coefficient for add-on insurance for both male and female subsamples. This results indicate a weak sign of adverse selection. We find a positive coefficient for public insurance in all the estimated models, but only statistically significant for ZINB2, the best model, for both genders. This result confirms the existence of moral hazard in the insurance market.

Although we show that the correlation between the demand for doctor and hospital is weak in the data, our bivariate NB model finds a positive and significant coefficient for public insurance and a positive and significant for add-on insurance for doctor's visit. This is also in contrast with the results by Riphahn et al (2003), who do not find any significant coefficient for the public insurance for doctor's visit in their bivariate model. Overall, our results find a strong evidence for moral hazard for visiting more doctors. The results provide significant evidence of how considering the over-dispersion nature of the data in the estimation process can provide more precise estimations and reveal a better understanding about health demand components. 


\section{Reference}

Ainsworth, 2007. Zero-inflated Spatial Models: web supplement. Lecture note. http://people.math.sfu.ca/ lmainswo/.

Amponsah, S., 2013. Adverse selection, moral hazard, and income effect in health insurance: the case of Ghana. Bulletin of Political Economy, Tokyo International University, 14, p.35.

Angers, J. and Biswas, A. 2003, 'A Bayesian analysis of zero-inflated generalized Poisson model'. Computational Statistics and Data Analysis, 42, 37-46.

Asante, F. and Aikins, M., 2008. Does the NHIS cover the poor. Ghana: Danida Health Sector Support Office.

Bago d’Uva, T., Jones, A., 2009, Health care utilization in Europe: new evidence from the ECHP, Journal of Health Economics, 28, 265-279.

Bajari, P., Hong, H. and Khwaja, A., 2011. A semiparametric analysis of adverse selection and moral hazard in health insurance contracts. Working Paper.

Bajari, P., Dalton, C., Hong, H. and Khwaja, A., 2014. Moral hazard, adverse selection, and health expenditures: A semiparametric analysis. The RAND Journal of Economics, 45(4), pp.747-763.

Bundorf, M.K., Herring, B. and Pauly, M., 2005. Health risk, income, and employment-based health insurance (No. w11677). National Bureau of Economic Research.

Cameron, C., Trivedi, T., 2013, Regression analysis of count data, Cambridge University Press.

Cardon, J.H., Handel, I., 2001. Asymmetric Information in Health Insurance: Evidence from the National Medical Expenditure Survey. The RAND Journal of Economics 32 (3), 408-427.

Carrol, R.j., Ruppert, D., Stefanski, L.A., and Crainiceanu (2006), "Measurement error in nonlinear models: A modern perspective, edition 2, London, Chapman and Hall/CRC.

Chen, X., Hong, H., and Nekipelov, D., (2011), “Nonlinear models of measurement error,” Journal of Economics Literature, 49(4), 901-937.

Buonaccorsi, J.P, (2010), “Measurement Error: Models, methods, and applications, Boca Raton, FL, Chapman and Hall/ CRC.

Cohen, A.C. (1960), "Estimation in a truncated Poisson distribution when zeros and ones are missing,” Journal of the American Statistical Association, 55, 342-348.

Famoye, F. 1995, Generalized binomial regression model. Biometrical Journal 37:581-594. 
Famoye, F. and Singh, K.P. (2006), 'Zero-inflated generalized Poisson regression model with an application to domestic violence data'. Journal of Data Science, 4, 117-130.

Greene, William H. (1994). "Some Accounting for Excess Zeros and Sample Selection in Poisson and Negative Binomial Regression Models". Working Paper EC-94-10: Department of Economics, New York University.

Greene, W., 2008, Functional forms for the negative binomial model for count data, Economic letters, Volume 99, Issue 3, June 2008, P. 585-590.

Gupta, P.L., Gupta, R.C. and Tripathi, R.C. (1996), 'Analysis of zero-adjusted count data'. Computational Statistics and Data Analysis, 23, 207-218.

Harris, T., Hilb, J., Hardin, J., 2014, Modeling count data with generalized distributions, The Stata Journal, 14, No.3, 562-579

Hilb, J., 2011, Negative Binomial Regression, Second Edition, Cambridge University Press.

Joe, H., Zhu, R., 2005, Generalized Poisson Distribution: the Property of Mixture of Poisson and Comparison with Negative Binomial Distribution, Biometrical Journal, Vol 74, Issue 2, p. 219229.

Johnson N.L., Kemp, A.W., Kotz, S., (2005), Univariate discrete distributions, edition3, New York, John Wiley.

Keane, M. and Stavrunova, O., 2016. Adverse selection, moral hazard and the demand for Medigap insurance. Journal of Econometrics, 190(1), pp.62-78.

Kirigia, J.M., Sambo, L.G., Nganda, B., Mwabu, G.M., Chatora, R. and Mwase, T., 2005. Determinants of health insurance ownership among South African women. BMC health services research, 5(1), p.1.

Kuhnert, P.M., Martin, T.G., Mengersen, K. and Possingham, H.P., 2005, 'Assessing the impacts of grazing levels on bird density in woodland habitat: a Bayesian approach using expert opinion’. Environmetrics, 16, 717-747.

Li, T., Trivedi, P.K., and Guo, J., (2003), “Modeling response bias in count: A structural approach with an application to the national crime victimization survey data," Sociological Methods and Research, 31, 415-545. 
Martin, T.G., Wintle, B.A., Rhodes, J.R., Kuhnert, P.M., Field, S.A., Low-Choy, S.J., Tyre, A.J. and Possingham, H.P. (2005), 'Zero tolerance ecology: improving ecological inference by modelling the source of zero observations’. Ecology Letters, 8, 1235-1246.

Marvasti, A., 2014, An estimation of the demand and supply for physician services using a panel data, Economic Modelling, Volume 43, December 2014, Pages 279-286.

Melkersson, M., and Rooth, D., (2000), "Modeling female fertility using inflated count data models,” Journal of Population Economics, 13, 189-203.

Neal, S., and Gaher, R. (2006), 'Risk for marijuana-related problems among college students: an application of zero-inflated negative binomial regression’. American Journal of Drug and Alcohol Abuse, 32, 41-53.

Pauly, Mark V. (1968),“The Economics of Moral Hazard.”American Economic Review, Vol. 58(3): 531-537.

Powell, D., 2014. Estimation of quantile treatment effects in the presence of covariates. Unpublished manuscript.

Powell, D. and Goldman, D., 2016. Disentangling Moral Hazard and Adverse Selection in Private Health Insurance (No. w21858). National Bureau of Economic Research

Rothschild, Michael, and Joseph E. Stiglitz. (1976), “Equilibrium in Competitive Insurance Markets: An Essay on the Economics of Imperfect Information.”Quarterly Journal of Economics, Vol. 90(4): 629-649.

Riphahn, T., Wambach, A., Million A., (2003), Incentive effects in the demand for health care: a behavioral panel count data estimation, Journal of Applied Economics, No. 18, 387-405.

Ridout, M., and Demetrio, C., and Hinde, J. (1998), 'Models for count data with many zeros'. International Biometric Conference. Cape Town, 1998.

Vuong, Quang. 1989. Likelihood ratio tests for model selection and non-nested hypotheses. Econometrica 57:307-33.

Wolfe, J.R. and Goddeeris, J.H., 1991. Adverse selection, moral hazard, and wealth effects in the Medigap insurance market. Journal of Health Economics, 10(4), pp.433-459. 


\section{Appendix A: Additional Tables}

\begin{tabular}{llllll}
\hline Variables & Description & Males $^{\mathrm{a}}$ & & Females $^{\mathrm{a}}$ & \\
\hline Docvis & Number of doctor visits in & 2.626 & $(5.21)$ & 3.791 & $(6.11)$ \\
Hos & Number of hospital visit & 0.128 & $(0.93)$ & 0.150 & $(0.83)$ \\
Age & Age & 42.653 & $(11.27)$ & 44.467 & $(11.32)$ \\
Hsat & Health satisfaction code 0 & 6.924 & $(2.25)$ & 6.634 & $(2.33)$ \\
Handdum & Person is handicapped (0/1) & 0.227 & $(0.42)$ & 0.200 & $(0.40)$ \\
Handper & Percentage degree of & 8.134 & $(20.33)$ & 5.791 & $(17.96)$ \\
Married & Person is married (0/1) & 0.765 & $(0.42)$ & 0.752 & $(0.43)$ \\
Educ & Years of schooling & 11.729 & $(2.44)$ & 10.876 & $(2.11)$ \\
Hhninc & Monthly household net & 3.591 & $(1.74)$ & 3.445 & $(1.80)$ \\
Hhkids & Children below age 16 in & 0.413 & $(0.49)$ & $(0.392)$ & $(0.49)$ \\
Self & Person is self-employed & 0.086 & $(0.28)$ & 0.037 & $(0.19)$ \\
Beamt & Person is civil servant (0/1) & 0.118 & $(0.32)$ & 0.028 & $(0.16)$ \\
Bluec & Person is blue collar & 0.340 & $(0.47)$ & 0.139 & $(0.35)$ \\
Working & Person is employed (0/1) & 0.850 & $(0.36)$ & 0.488 & $(0.50)$ \\
Public Insurance & Person is insured in public & 0.861 & $(0.35)$ & 0.913 & $(0.28)$ \\
Add-on & Person is insured in add-on & 0.018 & $(0.13)$ & 0.020 & $(0.14)$ \\
d85 & Year=1985 (0/1) & & & & \\
d86 & Year=1986 (0/1) & & & & \\
d87 & Year=1987 (0/1) & & & & \\
d88 & Year=1988 (0/1) & & & & \\
d91 & Year=1991 (0/1) & & & \\
d94 & Year=1994 (0/1) & & & \\
$N$ & Number of observations & & &
\end{tabular}

${ }^{a}$ mean, standard deviation in parentheses

Source: German Socioeconomic Panel (1984-1995). 
Table A2: Standard Distributions for Doctor Visit for Males (complete table)

\begin{tabular}{|c|c|c|c|c|c|c|}
\hline & Poisson & NB1 & NB2 & Gen_Possion & NBFamoy & GNBWaring \\
\hline \multicolumn{7}{|l|}{ Doctor visit } \\
\hline \multirow[t]{2}{*}{ Age } & -0.0239 & $-0.0477^{* * *}$ & $-0.0398^{* * *}$ & $-0.0496^{* * *}$ & $-0.0398^{* * *}$ & $-0.0533^{* * *}$ \\
\hline & $(0.0164)$ & $(0.0114)$ & $(0.0153)$ & $(0.0114)$ & $(0.0153)$ & $(0.0120)$ \\
\hline \multirow[t]{2}{*}{ Age2 } & $0.369^{* *}$ & $0.634^{* * *}$ & $0.547^{* * *}$ & $0.659^{* * *}$ & $0.547^{* * *}$ & $0.706^{* * *}$ \\
\hline & $(0.184)$ & $(0.129)$ & $(0.176)$ & $(0.130)$ & $(0.176)$ & $(0.137)$ \\
\hline \multirow[t]{2}{*}{ Hsat } & $-0.225^{* * *}$ & $-0.189^{* * *}$ & $-0.239^{* * * *}$ & $-0.188^{* * *}$ & $-0.239^{* * *}$ & $-0.203^{* * *}$ \\
\hline & $(0.00767)$ & $(0.00585)$ & $(0.00745)$ & $(0.00587)$ & $(0.00745)$ & $(0.00657)$ \\
\hline \multirow[t]{2}{*}{ Handdum } & 0.0690 & 0.0229 & -0.0209 & 0.0183 & -0.0209 & 0.0111 \\
\hline & $(0.0537)$ & $(0.0378)$ & $(0.0503)$ & $(0.0373)$ & $(0.0503)$ & $(0.0397)$ \\
\hline \multirow[t]{2}{*}{ Handper } & $0.00286^{* *}$ & $0.00414^{* * *}$ & $0.00661^{* * *}$ & $0.00430^{* * *}$ & $0.00661^{* * *}$ & $0.00505^{* * *}$ \\
\hline & $(0.00121)$ & $(0.000848)$ & $(0.00116)$ & $(0.000835)$ & $(0.00116)$ & $(0.000917)$ \\
\hline \multirow[t]{2}{*}{ Married } & 0.0583 & $0.130^{* * *}$ & 0.0658 & $0.135^{* * *}$ & 0.0658 & $0.139^{* * *}$ \\
\hline & $(0.0606)$ & $(0.0408)$ & $(0.0535)$ & $(0.0409)$ & $(0.0535)$ & $(0.0432)$ \\
\hline \multirow[t]{2}{*}{ Educ } & $-0.0235^{* * *}$ & -0.00955 & $-0.0262^{* * * *}$ & -0.00833 & $-0.0262^{* * * *}$ & -0.00971 \\
\hline & $(0.00873)$ & $(0.00672)$ & $(0.00910)$ & $(0.00688)$ & $(0.00910)$ & $(0.00725)$ \\
\hline \multirow[t]{2}{*}{ Bhninc } & $-0.0000222^{*}$ & -0.00000788 & $-0.0000192^{*}$ & -0.00000746 & $-0.0000192^{*}$ & -0.00000835 \\
\hline & $(0.0000121)$ & (0.00000853) & $(0.0000105)$ & (0.00000868) & $(0.0000105)$ & $(0.00000911)$ \\
\hline \multirow[t]{2}{*}{ Bhkids } & -0.0760 & $-0.0743^{* *}$ & $-0.0844^{*}$ & $-0.0766^{* *}$ & $-0.0844^{*}$ & $-0.0792^{* *}$ \\
\hline & $(0.0518)$ & $(0.0341)$ & $(0.0470)$ & $(0.0343)$ & $(0.0470)$ & $(0.0362)$ \\
\hline \multirow[t]{2}{*}{ Self } & $-0.211^{* *}$ & $-0.244^{* * *}$ & $-0.218^{* * *}$ & $-0.253^{* * *}$ & $-0.218^{* * *}$ & $-0.265^{* * *}$ \\
\hline & $(0.0847)$ & $(0.0616)$ & $(0.0784)$ & $(0.0628)$ & $(0.0784)$ & $(0.0656)$ \\
\hline \multirow[t]{2}{*}{ Beamt } & 0.0914 & 0.0278 & 0.0841 & 0.0273 & 0.0841 & 0.0254 \\
\hline & $(0.0809)$ & $(0.0623)$ & $(0.0766)$ & $(0.0630)$ & $(0.0766)$ & $(0.0664)$ \\
\hline \multirow[t]{2}{*}{ Bluec } & 0.0178 & -0.00948 & 0.0371 & -0.0116 & 0.0371 & -0.00956 \\
\hline & $(0.0486)$ & $(0.0374)$ & $(0.0458)$ & (0.0379) & $(0.0458)$ & $(0.0398)$ \\
\hline \multirow[t]{2}{*}{ Working } & -0.0554 & 0.0126 & -0.0155 & 0.0175 & -0.0155 & 0.0172 \\
\hline & $(0.0668)$ & $(0.0465)$ & $(0.0596)$ & $(0.0465)$ & $(0.0596)$ & $(0.0490)$ \\
\hline \multirow[t]{2}{*}{ Public Insurance } & 0.100 & 0.0607 & 0.0934 & 0.0595 & 0.0934 & 0.0578 \\
\hline & $(0.0702)$ & $(0.0539)$ & $(0.0635)$ & $(0.0549)$ & $(0.0635)$ & $(0.0577)$ \\
\hline Add-on Insurance & 0.0666 & $0.139^{*}$ & 0.0551 & $0.144^{*}$ & 0.0551 & $0.154^{*}$ \\
\hline & $(0.102)$ & $(0.0777)$ & $(0.0948)$ & $(0.0791)$ & $(0.0948)$ & $(0.0844)$ \\
\hline d85 & 0.0769 & $0.0615^{*}$ & $0.106^{*}$ & $0.0611^{*}$ & $0.106^{*}$ & $0.0669^{*}$ \\
\hline & $(0.0563)$ & $(0.0359)$ & $(0.0546)$ & $(0.0358)$ & $(0.0546)$ & $(0.0378)$ \\
\hline d86 & $0.215^{* * *}$ & $0.156^{* * *}$ & $0.226^{* * *}$ & $0.155^{* * *}$ & $0.226^{* * *}$ & $0.163^{* * *}$ \\
\hline & $(0.0597)$ & $(0.0365)$ & $(0.0581)$ & $(0.0365)$ & $(0.0581)$ & $(0.0386)$ \\
\hline d87 & 0.113 & $0.0967^{* *}$ & $0.123^{* *}$ & $0.0983^{* *}$ & $0.123^{* *}$ & $0.104^{* *}$ \\
\hline & $(0.0690)$ & $(0.0439)$ & $(0.0613)$ & $(0.0433)$ & $(0.0613)$ & $(0.0458)$ \\
\hline d88 & 0.0530 & $0.111^{* * *}$ & 0.0670 & $0.110^{* * *}$ & 0.0670 & $0.115^{* * *}$ \\
\hline & $(0.0558)$ & $(0.0360)$ & $(0.0544)$ & $(0.0361)$ & $(0.0544)$ & $(0.0379)$ \\
\hline d91 & -0.00397 & $0.145^{* * *}$ & -0.00366 & $0.152^{* * *}$ & -0.00366 & $0.151^{* * *}$ \\
\hline & (0.0609) & $(0.0373)$ & $(0.0531)$ & $(0.0374)$ & $(0.0531)$ & $(0.0393)$ \\
\hline d94 & $0.247^{* * *}$ & $0.268^{* * *}$ & $0.244^{* * *}$ & $0.278^{* * *}$ & $0.244^{* * *}$ & $0.289^{* * *}$ \\
\hline & $(0.0613)$ & $(0.0407)$ & $(0.0548)$ & (0.0409) & $(0.0548)$ & $(0.0430)$ \\
\hline Constant & $2.771^{* * *}$ & $2.776^{* * *}$ & $3.149^{* * *}$ & $2.780^{* * *}$ & $3.710^{* * *}$ & $2.929^{* * *}$ \\
\hline & $(0.336)$ & $(0.254)$ & (0.329) & $(0.258)$ & $(0.330)$ & $(0.273)$ \\
\hline Lndelta, & & $\begin{array}{l}1.581^{* * *} \\
(0.0365)\end{array}$ & & & & \\
\hline Lnalpha & & & $\begin{array}{l}0.561^{* * *} \\
(0.0270)\end{array}$ & & & \\
\hline Atanhdelta & & & & $0.726^{* * *}$ & & \\
\hline Lnphim1 & & & & & $-17.76^{* * *}$ & \\
\hline & & & & & (3.253) & \\
\hline Lntheta & & & & & $-0.561^{* * *}$ & \\
\hline & & & & & $(0.0270)$ & \\
\hline Lnrhom2 & & & & & & $0.783^{* * *}$ \\
\hline & & & & & & $(0.0981)$ \\
\hline Lnk & & & & & & $2.303^{* * *}$ \\
\hline & & & & & & $(0.130)$ \\
\hline Observations & 14243 & 14243 & 14243 & 14243 & 14243 & 14243 \\
\hline$A I C$ & 85593.4779 & 54865.9120 & 55006.8616 & 54700.9022 & 55008.8616 & 54528.6162 \\
\hline$B I C$ & 85759.8863 & 55039.8845 & 55180.8341 & 54874.8747 & 55190.3981 & 54710.1527 \\
\hline Dispersion & 6.67597 & & constant & 1.998817 & & \\
\hline Log lik. & -42774.7 & -27410.0 & -27480.4 & -27327.5 & -27480.4 & -27240.3 \\
\hline
\end{tabular}

Standard errors in parentheses

Source, German Socioeconomic Panel (1984-1995)

${ }^{*} p<0.10,{ }^{* *} p<0.05,{ }^{* * *} p<0.01$ 
Table A3: Standard Distributions for Doctor Visit for Females (complete)

\begin{tabular}{|c|c|c|c|c|c|c|}
\hline & Poisson & NB1 & NB2 & Gen_Possion & NBFamoy & GNBWaring \\
\hline \multicolumn{7}{|l|}{ Doctor visit } \\
\hline \multirow[t]{2}{*}{ Age } & -0.0132 & $-0.0322^{* * *}$ & $-0.0312^{* * *}$ & $-0.0347^{* * *}$ & $-0.0321^{* * *}$ & $-0.0400^{* * *}$ \\
\hline & $(0.0121)$ & $(0.00943)$ & $(0.0115)$ & $(0.00947)$ & $(0.0116)$ & $(0.0112)$ \\
\hline \multirow[t]{2}{*}{ Age2 } & 0.179 & $0.396^{* * *}$ & $0.373^{* * *}$ & $0.425^{* * *}$ & $0.382^{* * *}$ & $0.479^{* * *}$ \\
\hline & $(0.138)$ & $(0.107)$ & $(0.131)$ & $(0.107)$ & $(0.132)$ & $(0.127)$ \\
\hline \multirow[t]{2}{*}{ Hsat } & $-0.203^{* * *}$ & $-0.171^{* * *}$ & $-0.208^{* * *}$ & $-0.170^{* * *}$ & $-0.208^{* * *}$ & $-0.218^{* * *}$ \\
\hline & $(0.00641)$ & $(0.00507)$ & $(0.00631)$ & $(0.00506)$ & $(0.00636)$ & (0.00609) \\
\hline \multirow[t]{2}{*}{ Handdum } & $0.138^{* *}$ & $0.106^{* *}$ & $0.113^{* *}$ & $0.102^{* *}$ & $0.111^{* *}$ & $0.119^{* *}$ \\
\hline & $(0.0565)$ & $(0.0450)$ & $(0.0485)$ & $(0.0434)$ & $(0.0487)$ & $(0.0480)$ \\
\hline \multirow[t]{2}{*}{ Handper } & $0.00241^{* *}$ & $0.00254^{* * *}$ & $0.00436^{* * *}$ & $0.00254^{* * *}$ & $0.00457^{* * *}$ & $0.00418^{* * *}$ \\
\hline & (0.00108) & $(0.000867)$ & $(0.00106)$ & $(0.000846)$ & $(0.00110)$ & (0.000998) \\
\hline \multirow[t]{2}{*}{ Married } & 0.0272 & 0.0440 & 0.0282 & 0.0455 & 0.0284 & 0.0366 \\
\hline & $(0.0408)$ & $(0.0322)$ & $(0.0385)$ & $(0.0323)$ & $(0.0386)$ & $(0.0377)$ \\
\hline \multirow[t]{2}{*}{ Educ } & 0.0147 & $0.0138^{*}$ & 0.00773 & $0.0136^{*}$ & 0.00740 & 0.0121 \\
\hline & (0.00933) & $(0.00724)$ & $(0.00894)$ & $(0.00728)$ & $(0.00898)$ & $(0.00873)$ \\
\hline \multirow[t]{2}{*}{ Bhninc } & $-0.0000206^{* *}$ & -0.0000111 & $-0.0000162^{*}$ & -0.0000103 & $-0.0000161^{*}$ & -0.0000128 \\
\hline & (0.00000948) & $(0.00000740)$ & $(0.00000951)$ & $(0.00000746)$ & (0.00000955) & $(0.00000916)$ \\
\hline \multirow[t]{2}{*}{ Bhkids } & $-0.134^{* * *}$ & $-0.108^{* * *}$ & $-0.124^{* * *}$ & $-0.108^{* * *}$ & $-0.124^{* * *}$ & $-0.122^{* * *}$ \\
\hline & $(0.0416)$ & $(0.0311)$ & $(0.0376)$ & $(0.0311)$ & $(0.0375)$ & $(0.0367)$ \\
\hline \multirow[t]{2}{*}{ Self } & $-0.218^{* *}$ & $-0.223^{* * *}$ & $-0.242^{* * * *}$ & $-0.229^{* * *}$ & $-0.244^{* * *}$ & $-0.280^{* * * *}$ \\
\hline & $(0.0978)$ & $(0.0705)$ & $(0.0875)$ & $(0.0707)$ & $(0.0872)$ & $(0.0849)$ \\
\hline \multirow[t]{2}{*}{ Beamt } & -0.0711 & -0.00922 & -0.0198 & -0.00859 & -0.0183 & -0.0499 \\
\hline & $(0.117)$ & $(0.0848)$ & $(0.128)$ & (0.0859) & $(0.129)$ & $(0.107)$ \\
\hline \multirow[t]{2}{*}{ Bluec } & -0.0354 & $-0.0718^{*}$ & -0.0401 & $-0.0772^{* *}$ & -0.0406 & -0.0730 \\
\hline & $(0.0555)$ & $(0.0392)$ & $(0.0497)$ & $(0.0392)$ & $(0.0495)$ & $(0.0471)$ \\
\hline \multirow[t]{2}{*}{ Working } & 0.0149 & 0.0247 & 0.0305 & 0.0264 & 0.0313 & 0.0363 \\
\hline & $(0.0392)$ & $(0.0294)$ & $(0.0354)$ & $(0.0295)$ & $(0.0354)$ & $(0.0347)$ \\
\hline Public Insurance & $0.131^{* *}$ & 0.0790 & 0.0953 & 0.0715 & 0.0935 & 0.0787 \\
\hline & $(0.0599)$ & $(0.0489)$ & $(0.0639)$ & $(0.0499)$ & $(0.0643)$ & $(0.0598)$ \\
\hline Add-on Insurance & 0.0207 & $0.126^{*}$ & 0.0309 & $0.138^{* *}$ & 0.0312 & 0.111 \\
\hline & $(0.0888)$ & $(0.0682)$ & $(0.0769)$ & $(0.0687)$ & (0.0769) & $(0.0794)$ \\
\hline d85 & -0.0362 & -0.0326 & -0.0127 & -0.0303 & -0.0119 & -0.0218 \\
\hline & $(0.0473)$ & (0.0319) & $(0.0449)$ & $(0.0318)$ & $(0.0450)$ & $(0.0386)$ \\
\hline d86 & $0.0941^{* *}$ & $0.0837^{* *}$ & $0.102^{* *}$ & $0.0836^{* *}$ & $0.102^{* *}$ & $0.114^{* * *}$ \\
\hline & $(0.0449)$ & (0.0329) & $(0.0430)$ & (0.0328) & $(0.0433)$ & $(0.0383)$ \\
\hline d87 & -0.0843 & -0.0750 & -0.0531 & -0.0690 & -0.0515 & -0.0701 \\
\hline & $(0.0642)$ & $(0.0485)$ & $(0.0566)$ & $(0.0471)$ & (0.0569) & $(0.0529)$ \\
\hline d88 & $-0.180^{* * * *}$ & $-0.0677^{* *}$ & $-0.176^{* * *}$ & $-0.0670^{* *}$ & $-0.176^{* * *}$ & $-0.145^{* * *}$ \\
\hline & $(0.0448)$ & (0.0315) & $(0.0439)$ & (0.0315) & $(0.0441)$ & $(0.0384)$ \\
\hline d91 & $-0.154^{* * *}$ & 0.0108 & $-0.138^{* * * *}$ & 0.0202 & $-0.138^{* * * *}$ & $-0.0688^{*}$ \\
\hline & $(0.0456)$ & $(0.0326)$ & $(0.0441)$ & $(0.0327)$ & $(0.0442)$ & $(0.0402)$ \\
\hline d94 & $0.197^{* * *}$ & $0.186^{* * *}$ & $0.221^{* * *}$ & $0.191^{* * *}$ & $0.222^{* * *}$ & $0.252^{* * *}$ \\
\hline & $(0.0481)$ & $(0.0370)$ & $(0.0464)$ & $(0.0371)$ & $(0.0466)$ & $(0.0433)$ \\
\hline Constant & $2.547^{* * *}$ & $2.731^{* * *}$ & $3.024^{* * *}$ & $2.777^{* * *}$ & $3.184^{* * *}$ & $3.190^{* * *}$ \\
\hline & $(0.282)$ & $(0.224)$ & $(0.273)$ & $(0.227)$ & $(0.276)$ & $(0.267)$ \\
\hline Lndelta & & $\begin{array}{l}1.549^{* * * *} \\
(0.0349)\end{array}$ & & & & \\
\hline Lnalpha & & & $\begin{array}{l}0.188^{* * *} \\
(0.0259)\end{array}$ & & & \\
\hline Atanhdelta & & & & $0.711^{* * *}$ & & \\
\hline & & & & (0.0108) & & \\
\hline Lnphim1 & & & & & $-4.580^{* * *}$ & \\
\hline & & & & & $(0.762)$ & \\
\hline Lntheta & & & & & $-0.133^{* * *}$ & \\
\hline & & & & & $(0.0443)$ & \\
\hline Lnrhom2 & & & & & & $1.014^{* * *}$ \\
\hline & & & & & & $(0.113)$ \\
\hline Lnk & & & & & & $0.283^{* * *}$ \\
\hline & & & & & & $(0.0764)$ \\
\hline Observations & 13083 & 13083 & 13083 & 13083 & 13083 & 13083 \\
\hline$A I C$ & 91844.4596 & 60731.5683 & 60570.6248 & 60521.2975 & 60569.0256 & 60307.5709 \\
\hline$B I C$ & 92008.9991 & 60903.5869 & 60742.6434 & 60693.3160 & 60748.5232 & 60487.0686 \\
\hline Log lik. & -45900.2 & -30342.8 & -30262.3 & -30237.6 & -30260.5 & -30129.8 \\
\hline Dispersion & 6.689348 & & 1.487322 & & & \\
\hline
\end{tabular}

Standard errors in parentheses

Source, German Socioeconomic Panel (1984-1995)

${ }^{*} p<0.10,{ }^{* *} p<0.05,{ }^{* * *} p<0.01$ 
Table A4: Predicted and original numbers of doctor visits ( Standard Poisson)

\begin{tabular}{llllllll}
\hline Doctor visit & 0 & 1 & 2 & 3 & 4 & 5 & 6 \\
\hline 0 & 838 & 3,564 & 1,089 & 437 & 165 & 77 & 35 \\
1 & 183 & 976 & 424 & 205 & 85 & 36 & 19 \\
2 & 104 & 721 & 421 & 789 & 87 & 63 & 22 \\
3 & 56 & 441 & 289 & 158 & 103 & 74 & 25 \\
4 & 19 & 225 & 162 & 111 & 60 & 38 & 23 \\
5 & 12 & 135 & 124 & 72 & 56 & 42 & 18 \\
6 & 7 & 109 & 92 & 64 & 57 & 26 & 23 \\
7 & 3 & 60 & 49 & 36 & 22 & 15 & 5 \\
8 & 3 & 52 & 64 & 30 & 26 & 14 & 13 \\
9 & 1 & 22 & 15 & 16 & 16 & 7 & 5 \\
\hline Total & 1,226 & 6,305 & 2,729 & 1,318 & 677 & 392 & 188
\end{tabular}

Table A5: Predicted and original numbers of doctor visits ( ZI Poisson )

\begin{tabular}{llllllll}
\hline Doctor visit & 0 & 1 & 2 & 3 & 4 & 5 & 6 \\
\hline 0 & 1,441 & 2,931 & 981 & 502 & 205 & 96 & 44 \\
1 & 294 & 845 & 378 & 239 & 100 & 48 & 24 \\
2 & 167 & 643 & 380 & 211 & 103 & 62 & 39 \\
3 & 94 & 390 & 256 & 175 & 114 & 79 & 39 \\
4 & 34 & 206 & 143 & 112 & 65 & 46 & 29 \\
5 & 21 & 122 & 112 & 68 & 66 & 43 & 29 \\
6 & 17 & 92 & 75 & 79 & 54 & 29 & 29 \\
7 & 10 & 50 & 38 & 46 & 23 & 14 & 9 \\
8 & 8 & 44 & 54 & 39 & 25 & 18 & 12 \\
9 & 3 & 18 & 18 & 18 & 16 & 9 & 8 \\
\hline Total & 2,089 & 5,341 & 2,427 & 1,489 & 771 & 444 & 262
\end{tabular}

Table A6: Predicted and original numbers of doctor visits (Standard NB2)

\begin{tabular}{llllllll}
\hline Doctor visit & 0 & 1 & 2 & 3 & 4 & 5 & 6 \\
\hline 0 & 1,170 & 3,360 & 971 & 406 & 172 & 63 & 42 \\
1 & 242 & 954 & 386 & 199 & 73 & 39 & 23 \\
2 & 173 & 735 & 369 & 187 & 72 & 58 & 33 \\
3 & 77 & 442 & 266 & 147 & 91 & 96 & 35 \\
4 & 27 & 235 & 145 & 97 & 56 & 40 & 21 \\
5 & 18 & 139 & 116 & 60 & 60 & 38 & 23 \\
6 & 10 & 113 & 80 & 66 & 45 & 24 & 23 \\
7 & 7 & 59 & 44 & 38 & 21 & 12 & 4 \\
8 & 5 & 55 & 54 & 33 & 23 & 15 & 9 \\
9 & 1 & 22 & 13 & 16 & 15 & 7 & 4 \\
\hline Total & 1,694 & 6,114 & 2,444 & 1,249 & 628 & 365 & 217
\end{tabular}

Table A7: Predicted and original numbers of doctor visits (ZINB2 )

\begin{tabular}{llllllll}
\hline Doctor visit & 0 & 1 & 2 & 3 & 4 & 5 & 6 \\
\hline 0 & 1,446 & 2,932 & 1,020 & 478 & 184 & 94 & 41 \\
1 & 289 & 860 & 385 & 238 & 85 & 40 & 27 \\
2 & 171 & 647 & 387 & 216 & 85 & 55 & 41 \\
3 & 97 & 388 & 266 & 177 & 102 & 68 & 44 \\
4 & 35 & 210 & 145 & 109 & 64 & 39 & 27 \\
5 & 20 & 126 & 110 & 81 & 53 & 40 & 28 \\
6 & 18 & 95 & 82 & 72 & 45 & 36 & 23 \\
7 & 8 & 54 & 39 & 42 & 23 & 13 & 7 \\
8 & 8 & 47 & 52 & 41 & 24 & 16 & 10 \\
9 & 3 & 18 & 9 & 19 & 12 & 14 & 5 \\
\hline Total & 2,095 & 5,377 & 2,495 & 1,473 & 677 & 415 & 253
\end{tabular}


Table A8.1: (NB2) Predicted and actual probabilities

\begin{tabular}{lllll}
\hline Count & Actual & Predicted & $\mid$ Diff $\mid$ & Pearson \\
\hline 0 & 0.440 & 0.428 & 0.012 & 4.992 \\
1 & 0.138 & 0.180 & 0.042 & 136.630 \\
2 & 0.116 & 0.106 & 0.011 & 15.150 \\
3 & 0.085 & 0.069 & 0.016 & 52.273 \\
4 & 0.049 & 0.048 & 0.001 & 0.617 \\
5 & 0.036 & 0.034 & 0.001 & 0.800 \\
6 & 0.030 & 0.025 & 0.005 & 13.029 \\
7 & 0.016 & 0.019 & 0.004 & 9.693 \\
8 & 0.016 & 0.015 & 0.001 & 0.983 \\
9 & 0.007 & 0.012 & 0.005 & 25.303 \\
10 & 0.015 & 0.009 & 0.006 & 55.167 \\
\hline Sum & 0.948 & 0.944 & 0.103 & 314.635
\end{tabular}

Table A8.2: (ZINB2) Predicted and actual probabilities

\begin{tabular}{lllll}
\hline Count & Actual & Predicted & $\mid$ Diff $\mid$ & Pearson \\
\hline 0 & 0.440 & 0.446 & 0.006 & 1.139 \\
1 & 0.138 & 0.145 & 0.007 & 5.034 \\
2 & 0.116 & 0.099 & 0.017 & 40.468 \\
3 & 0.085 & 0.071 & 0.014 & 40.148 \\
4 & 0.049 & 0.052 & 0.003 & 1.765 \\
5 & 0.036 & 0.038 & 0.003 & 2.878 \\
6 & 0.030 & 0.029 & 0.001 & 0.591 \\
7 & 0.016 & 0.022 & 0.007 & 28.703 \\
8 & 0.016 & 0.017 & 0.001 & 1.759 \\
9 & 0.007 & 0.014 & 0.006 & 44.089 \\
10 & 0.015 & 0.011 & 0.005 & 26.856 \\
\hline Sum & 0.948 & 0.945 & 0.070 & 193.429
\end{tabular}

Table A8.3: (Poisson)Predicted and actual probabilities

\begin{tabular}{lllll}
\hline Count & Actual & Predicted & $\mid$ Diff $\mid$ & Pearson \\
\hline 0 & 0.440 & 0.441 & 0.000 & 0.000 \\
1 & 0.138 & 0.056 & 0.082 & 1724.211 \\
2 & 0.116 & 0.085 & 0.032 & 169.678 \\
3 & 0.085 & 0.093 & 0.008 & 10.143 \\
4 & 0.049 & 0.084 & 0.035 & 211.840 \\
5 & 0.036 & 0.068 & 0.033 & 222.485 \\
6 & 0.030 & 0.051 & 0.021 & 124.089 \\
7 & 0.016 & 0.037 & 0.021 & 175.386 \\
8 & 0.016 & 0.026 & 0.010 & 55.840 \\
10 & 0.015 & 0.012 & 0.003 & 9.078 \\
\hline Sum & 0.948 & 0.971 & 0.256 & 2796.77
\end{tabular}




\section{Appendix B: Model Specifications}

To account for over-dispersion and deviations from $E\left(Y_{i}\right)=V\left(Y_{i}\right)=\mu_{i}$ in the Poisson distribution, a new distribution is obtained by adding an individual unobserved effect $\left(u_{i}\right)$ to the log of the mean of the Poisson model, $\ln \left(\right.$ mean $\left._{i}\right)=\ln \left(\mu_{i}\right)+\ln \left(u_{i}\right)$. Thus, by defining different distributions for $u_{i}$, new versions of the Poisson distribution are created. Table B1 presents a list of those distributions, known as standard distributions in this paper, with their variances. A Gamma distribution for $u_{i}$, for example, gives a Negative Binomial 2 (NB2) distribution with mean $\mu_{i}$ and conditional variance $\mu_{i}+\alpha \mu_{i}{ }^{2}$, with the constant parameter $\alpha$ controlling for heterogeneity or dispersion among individuals. The additional parameter $p$ in the Power Negative Binomial (NB-P) distribution, introduced by Green (2008), provides NB1 or NB2 distributions when $p=1$ or $p=2$, respectively. Also, the Heterogeneous NB2 model allows the heterogeneity explained by $\alpha$ in the NB2 distribution to be a function of the individual's characteristics $\left(z_{i}\right), \alpha=\exp \left(z_{i} \gamma\right)$. Thus, $\alpha$ can vary among individuals. In special case, where $\phi \rightarrow 1$, the variance of Famoye's (1995) distribution approaches to that of the NB. The Waring Negative Binomial distribution introduce by Irwin (1968) converges to NB if $k \rightarrow \frac{1}{\alpha}, \rho \rightarrow \infty$. Also, if $\delta=0$, the GP distribution reduces to the usual Poisson distribution with parameter $\theta_{i}$. (See Hilbe $(2011,2014)$ for more details)

Table B1: The list of standard distributions Distribution

Poisson

Negative Binomial 1 (NB1)

Negative Binomial 2 (NB2)

Generalized Negative Binomial (NB-P)

Heterogeneous Negative Binomial (NB-H)

Generalized Negative Binomial (Famoy)

Waring Negative Binomial (NBW)

Generalized Poisson, (GP)

\section{Variance}

$\mu$ (where $\ln \mu=X \beta$ )

$\mu+\alpha \mu$ (where $\alpha$ is the dispersion parameter)

$\mu+\alpha \mu^{2}$

$\mu+\alpha \mu^{p}$

$\mu+\alpha_{i} \mu^{2}$ ( where $\left.\alpha_{i}=z_{i} \gamma\right)$

$\theta \mu(1-\phi \mu)(1-\phi \mu)^{-3}$

$\mu+\mu\left(\frac{k+1}{\rho-2}\right)+\mu^{2}\left\{\frac{k+\rho-1}{k(\rho-2)}\right\}$

$\frac{1}{(1-\delta)^{2}} \mu$

\section{Zero-inflated count models}

As Hilbe (2011) discuss, the framework of zero-inflated models are based on separating zero outcomes and positive ones. The probability of zero outcomes results from the group of individuals who are not the subject of an event $(Q(0)$ for those who do not have physician to visit), and those who are the subject of 
the event but with zero outcome $(\mathrm{P}(0)$ for those who do not visit their physicians). The two part of the model is written as:

The probability of a zero outcome for the system is given by9:

$$
\operatorname{Pr}(y=0)=Q(0)+\{1-B(0)\} \operatorname{Pr}(0)
$$

And the probability of a nonzero count is10:

$$
\operatorname{Pr}(y=k ; k>0)=\{1-B(0)\} \operatorname{Pr}(k)
$$

A Probit or logit model estimates $Q(0)$ while one of the standared models in Table (1) estimates $\operatorname{Pr}(k), k=0,1, \ldots n$. The mixture model have more power in explaining over-dispersion in the data (see also Hilbe and Greene (2008)).

- Table B2 presents different zero-inflated distributions that are used in the next sections for the purpose of estimation and comparison.

\footnotetext{
Zero-inflated Poisson (ZIP)

Zero-inflated Negative Binomial 1 (ZINB1)

Zero-inflated Negative Binomial 2 (ZINB2)

Zero-inflated Generalized NB (ZINB-P)

Zero-inflated Poisson Inverse Gaussian, (ZIPIG)

Zero-inflated Generalized Poisson, (ZIGP)

Zero-Inflated 3-parameter Waring NB (ZINBW)

Zero-inflated 3-parameter Famoye NB (ZINBF)
}

\footnotetext{
${ }^{9}$ Stata gives this probability using the command: predict fo, $\operatorname{pr}(0)$

${ }^{10}$ Stata gives this probability using the command: predict $\mathrm{fk}, \operatorname{pr}(\mathrm{k})$
} 